\title{
Conocimiento sociodemográfico y respuesta institucional a una pandemia. El caso de México
}

\section{Demographic knowledge and institutional response to a pandemic. The case of Mexico}

\author{
Carlos Welti-Chanes y Alfonso C. Ramírez-Penagos \\ Instituto de Investigaciones Sociales de la Universidad Nacional \\ Autónoma de México, México
}

\begin{abstract}
Resumen
El artículo hace evidente la necesidad de tomar en cuenta las características de los grupos demográficos que conforman un país y el entorno de una sociedad globalizada que interactúa con ella, para tomar decisiones debidamente fundadas con el objetivo de enfrentar un fenómeno, cuyas consecuencias pueden ser catastróficas como es el caso de una pandemia. El texto hace referencia a la respuesta no farmacológica a una pandemia para disminuir el nivel de contagios entre la población y que incluye medidas como el aislamiento social, la cuarentena y el cierre parcial o total de áreas en las que se desarrollan actividades que implican la interacción en tiempo real entre personas y que involucran contacto físico, lo que hace necesario evaluar los posibles efectos, derivados de su ubicación socialmente estructurada en organizaciones como la empresa, la escuela o la familia. Las políticas públicas para enfrentar la pandemia son el núcleo central del análisis y, específicamente, las acciones gubernamentales que se diseñan o se deberían diseñar en diversos ámbitos, y que se ponen a funcionar a través de organizaciones concretas con este objetivo. También los roles de la familia y las organizaciones que forman parte del mercado son analizados en este contexto.
\end{abstract}

Palabras clave: Pandemia, políticas públicas, demografía.

Abstract

The article makes evident the need to take into account the demographic characteristics of the population including those of the globalized society that interacts with it, to make founded decisions, in the área of public policy in order to face a phenomenon, whose consequences may be catastrophic such as a pandemic. The text analyses the non-pharmacological response, to a pandemic to reduce the level of contagion among the population and that includes measures such as social isolation, quarantine and the partial or total closure of areas whose activities require the interaction in real time between individuals implying physical contact between them, and it shows the need to evaluate the possible effects in people derived from their socially structured location in organizations such as the market, the school or the family. Public policies to face the pandemic are the central nucleus of the analysis and specifically, the government actions that are designed or should be designed in various áreas, and that are put into operation through specific organizations with this objective.

Key words: Pandemic, public policies, demography. 


\section{INTRODUCCIÓN}

finales del mes de marzo del año 2009, en una fecha que coin-
cidía con el inicio de un brote epidémico causado por un nuevo
serotipo de virus de influenza, que había sido detectado en el en un evento dedicado a analizar la problemática demográfica del país y los avances y retos de la política de población en el sexenio 2006-2012, ante una pregunta específica sobre las acciones de salud pública que se podrían visualizar para evitar una epidemia, dadas las condiciones demográficas de México, respondía que, lo más probable es que se promovieran medidas para evitar los contagios y que, en el extremo significaban que todas las personas se deberían quedar en su casa, porque la sociedad no se había preparado adecuadamente para enfrentar este tipo de problemas de salud y que, para poner un ejemplo didáctico, equivalía a tratar de incidir sobre la mortalidad asociada a los accidentes viales haciendo que los vehículos automotores no circularan, cuando no se han tomado otro tipo de medidas preventivas para incidir en la mortalidad por esta causa. Medida esta última que, por cierto, se aplica para tratar de disminuir la contaminación ambiental en la Ciudad de México. Algunos asistentes a la reunión consideraron exagerada esta opinión. Sin embargo, en el mes de abril, después de que el gobierno entregara millones de cubrebocas a la población en el Distrito Federal, las escuelas, desde el nivel básico hasta las universidades, fueron cerradas "hasta nuevo aviso" y las unidades económicas de diversos sectores, cambiaron sus rutinas de trabajo para disminuir las probabilidades de contagio. Era la primera vez en la historia del país que la gente, por recomendación de las autoridades, "se quedaba en casa" para enfrentar una epidemia. Se promocionó además la necesidad de que las personas se lavaran las manos varias veces al día como medida de higiene que, aunque es obvia no es una costumbre arraigada en la sociedad.

Las medidas descritas, que se tomaron de manera inicial, tuvieron efectos sobre la incidencia de la enfermedad asociada al virus y la mortalidad. Se contabilizaron según cifras oficiales poco más de 100 defunciones entre marzo y junio de 2009 por esta causa ${ }^{1}$ (Gutiérrez-Gómez et al., 2009; González et al., 2011).

Esta experiencia obligó a volver a pensar seriamente en los riesgos a los que está expuesta la población por sus actuales condiciones demográficas, cuando un nuevo virus afecte su salud. Sin embargo, a pesar de lo que se

\footnotetext{
${ }^{1}$ Reporte epidemiológico de la SSA 2009, citado por Gutiérrez-Gómez et al. (2009).
} 
afirme en la actualidad en sentido contrario, y por situaciones que tienen diversos orígenes, la visión estratégica que, de manera explícita o implícita, debe formar parte de la planeación de las acciones de las organizaciones encargadas del cuidado de la salud, no ha tomado en cuenta estos riesgos y junto con los objetivos de largo plazo, no se incorporan las posibles acciones coyunturales para enfrentarlos.

Para el diseño e implementación de las políticas públicas para enfrentar este tipo de riesgos, el conocimiento del estado actual de la población y su evolución desde el punto de vista demográfico, es primordial y lo es también, para otros sectores de la sociedad que incluyen a las empresas, las organizaciones de la sociedad civil y las familias.

La atención de los especialistas desde el inicio de la pandemia en el año 2019, ha estado centrada en el envejecimiento de la población, al considerar la edad avanzada como factor de riesgo, que incrementa la probabilidad de morir cuando una persona se ve afectada por el nuevo virus. Sin embargo, los factores demográficos asociados al avance o contención de la pandemia, son múltiples y deben hacerse evidentes para que los individuos encargados de tomar decisiones tengan fundamentos científicos para hacerlo. Desde luego, la edad de las personas es una variable demográfica básica relacionada con la morbilidad y la mortalidad de las personas, igual que el sexo; pero además, deben ser consideradas características de las unidades sociales básicas como la familia y los hogares desde el punto de vista demográfico, por el efecto que las medidas de política pública para enfrentar una pandemia tendrán sobre las personas que forman parte de estas unidades dadas las diferencias entre ellas en su estructura y el rol individual de quienes las integran.

También, la distribución de la población en el territorio es una característica demográfica fundamental para tenerse en cuenta, porque la concentración y dispersión de la población no sólo está asociada a la interacción diferencial de las personas en las áreas urbanas y en las áreas rurales, también a las condiciones sanitarias y al acceso a los servicios de cuidado a la salud, a la información y a las comunicaciones.

Otro factor que debe tomarse en cuenta, es la movilidad de la población, que incluye, tanto a la migración representada por el cambio de lugar de residencia, como la que se produce de manera recurrente cuando las personas se trasladan día con día desde sus hogares a su lugar de trabajo, de estudio o incluso para recibir tratamiento médico. Estas acciones incrementan los riesgos de contagio por el virus, pero no puede recomendarse o imponerse a las personas, la permanencia en casa o la salida excepcional desde ésta, 
para realizar algunas actividades, sin conocer lo que puede implicar esta acción a partir de las características de las personas y las organizaciones de las que forman parte, como ya se mencionó, desde el punto de vista demográfico, pero también de salud, económico, cultural y político, cuyo análisis en profundidad con excepción del primero, supera los objetivos de este texto.

El conocimiento demográfico exige contar con información que lo haga posible, en el caso de México, es indispensable hacer evidente la potencialidad del sistema nacional de información sociodemográfica, así como sus limitaciones y las necesidades de contar con cierto tipo de datos demográficos, para la definición de las políticas y programas específicos que tengan como objetivo enfrentar una pandemia.

\section{Planeación estratégica y respuestas coyunturales EN UNA PANDEMIA. LA ADMINISTRACIÓN DE RIESGOS. GESTIÓN DEL RIESGO Y DEMOGRAFÍA}

Una de las ventajas de que en el diseño de una política pública, se utilice el conocimiento de la evolución demográfica del país es que, además de hacer evidentes los escenarios que pueden presentarse en el futuro y por tanto, fundamenta la visión estratégica que debe ser inherente a toda acción de gobierno, posibilita la identificación de situaciones coyunturales asociadas a las características de la población, que generen riesgos significativos para la sobrevivencia y desarrollo de la sociedad y que, por tanto, deben formar parte de planes de acción de corto y mediano plazo.

Para una visión de largo plazo, las proyecciones de población, son la herramienta para estimar su volumen y su estructura en una serie de cortes transversales definidos en el tiempo y en el espacio geográfico en que las personas residen a partir de las hipótesis que, sobre los componentes del cambio poblacional elaboran los especialistas basados en el conocimiento de sus determinantes. Este conocimiento hace que las proyecciones de población sean cada vez más precisas siempre y cuando, una situación extraordinaria no considerada, modifique el comportamiento de cierta variable. Por esta razón las proyecciones más utilizadas en la actualidad, definen escenarios que se pueden presentar con cierta probabilidad, si determinadas condiciones se cumplen. Los sistemas de información modernos hacen posible que la lista de las condiciones extraordinarias que se identifican, sea cada vez más amplia. 
Es en el marco general de la evolución demográfica que se inserta la planeación estratégica y en el cual deben estimarse los riesgos asociados a sus características.

La noción de riesgo constituye un elemento central en este análisis y para el caso de las respuestas institucionales a una pandemia, resulta indispensable diferenciar entre riesgos sociales y riesgos individuales.

A partir de la publicación de La Sociedad del Riesgo de Beck (1986), la reflexión sobre la noción de riesgo se amplió para hacer evidente que, paradójicamente, el propio desarrollo de la sociedad, la "modernización" en la conceptualización de Beck, que incide sobre el peligro y la vulnerabilidad, como componentes de la ecuación que define el riesgo, genera a su vez nuevos peligros y vulnerabilidades y, lo que es más importante, hace que grupos sociales que se consideraban exentos de riesgo o con un riesgo mínimo de enfrentar eventos catastróficos por tener garantizado el acceso a recursos económicos estructuralmente disponibles, se vean inmersos en situaciones que previamente no se presentaban.

Vale la pena recordar que, en el caso de México, al surgir la pandemia, hubo políticos del partido gobernante que se refirieron a que, sólo los ricos serían víctimas de la enfermedad. Por ejemplo, el Sr. Gobernador del Estado de Puebla, en un evento público declaró: “¿Quiénes están contagiados ahorita?... La mayoría son (sic) gente acomodada eh. ¿Sí lo saben o no? Si ustedes son ricos, tienen el riesgo. Si ustedes son pobres, no. Los pobres estamos inmunes" (Conferencia de prensa del gobernador del Estado de Puebla, realizada el 25 de marzo de $2020^{2}$ ). También, el Presidente de la República, consideró que: "en el caso del agravamiento de la crisis (del coronavirus) "el escudo protector... es el detente",... "detente enemigo que el Corazón de Jesús está conmigo... y no lo traje......es un trébol" (Conferencia diaria correspondiente al 17 de marzo de $2020^{3}$ ). No parece que las autoridades mencionadas, tuvieran conciencia del riesgo de sufrir el contagio del virus.

Se mencionan estás referencias, porque la minimización del riesgo de que una persona pudiera ser contagiada del virus, por parte de personalidades que tienen gran influencia entre diversos sectores de la población, pudo haber tenido impacto sobre las conductas de la población y en última instancia, sobre la propagación del virus e incluso, sobre la letalidad asociada, al conducirse sin la debida protección.

\footnotetext{
2 Tomado de: https://www.youtube.com/watch?v=1KG2uDj6Gk0. (Noticiero conducido por Denisse Maerker).

3 Tomado de: https://www.youtube.com/watch?v=CRSo5QZJHZg
} 
Aunque el riesgo se encuentra asociado a las características individuales de los seres humanos, existen una serie de condiciones que influyen sobre cada uno de sus componentes; de manera central, condiciones estructurales, derivadas de la posición que se ocupa en la sociedad y que pueden ser modificadas por determinados arreglos institucionales que afectan las relaciones entre los propios individuos, o entre los individuos y las organizaciones creadas para satisfacer sus necesidades.

Los seres humanos al identificar los riesgos que ponen en peligro su existencia, o cuando crecen los niveles de incertidumbre derivados del escaso conocimiento sobre la evolución de los acontecimientos que le afectan, perciben que la mejor manera de enfrentarlos es la vida en sociedad. Incluso, puede decirse, que cualquiera que sea la explicación teórica sobre el origen de la sociedad, es la necesidad de seguridad y de disminución de los riesgos, la que da origen al contrato social y la forma de enfrentarlos es la que a su vez genera los tipos de gobierno que guían a una sociedad. Un sistema democrático garantiza que los intereses de todos los grupos sociales se tomen en cuenta, al definir las acciones que busquen su seguridad, cuando existe el conocimiento suficiente para ello.

Si se parte del hecho de que el riesgo es una función de los peligros y la vulnerabilidad, tratar de disminuirlo requiere identificar cada uno de los factores que inciden sobre sus componentes, asociados a las características de la población y es el Estado, el que debe responder a la necesidad de lograr el bienestar de sus miembros disminuyendo peligros o vulnerabilidades.

Además del Estado, la historia reciente de la humanidad muestra que las constantes etapas de crisis que las sociedades nacionales vivieron en el siglo XX, hicieron indispensable la intervención de la sociedad civil organizada para regular procesos que de otra manera se convertían en obstáculos al desarrollo. La naturaleza de las intervenciones ha sido diversa, junto con su grado de intensidad, pero se puede afirmar que en los países en donde está participación es real y está garantizada por el Estado, se han alcanzado los mayores niveles de bienestar y las menores inequidades, lo que permite suponer que una sociedad democrática en la que participan las organizaciones de la sociedad civil, permite atender de mejor manera las necesidades de los individuos. Es, por cierto, en estas sociedades en las cuales los sistemas de seguridad social están más desarrollados y en las que la estabilidad política es una de sus características.

Nuestra existencia transcurre en un entorno en el cual enfrentar el riesgo es una constante. Riesgo de la pérdida del patrimonio, o que éste sufra 
algún un daño, riesgo de adquirir una enfermedad o tener un accidente, riesgo de perder las fuentes de ingreso, riesgo incluso, de perder la vida.

La intensidad que adquiere el riesgo depende de la exposición a los peligros que se derivan de las actitudes y prácticas que asuma la población, del grado de vulnerabilidad individual y del entorno institucional que incida sobre peligro y vulnerabilidad.

Si bien cada individuo asume comportamientos particulares para enfrentar los riesgos, hay en ellos elementos comunes que se derivan de sus propias características o del ambiente social en el que se encuentra inserto y que le son propias a cada grupo social. Sin embargo, la idea de que los riesgos están asociados a la inserción estructural de los individuos se ha modificado ante las evidencias de que la vulnerabilidad es cada vez menos diferencial, porque los peligros adquieren una condición universal asociada precisamente con procesos demográficos, como son el crecimiento de la población, la concentración en ciertas áreas, la movilidad y desde luego, el envejecimiento al que todos aspiramos.

Un análisis de las formas de enfrentar el riesgo hace evidente la capacidad que se tiene para ello. La educación y el acceso a recursos materiales juegan un papel fundamental en la generación de esta capacidad.

Una respuesta colectiva a los riesgos además de que es una decisión económicamente sostenible, es socialmente justificable, porque la sociedad no es homogénea y esto se manifiesta en la dimensión de los riesgos que se derivan al hecho de pertenecer a determinado grupo social. Es el reconocimiento de las condiciones diferenciales de vulnerabilidad, el origen de la gestión pública del riesgo a través de la seguridad social.

Vivimos en una sociedad en la cual los riesgos se multiplican (Beck, 2006). Sólo desde el punto de vista demográfico y sin que esto signifique la adopción de una posición maltusiana, el crecimiento poblacional genera una demanda de bienes que debe ser satisfecha intensificando la explotación de los recursos naturales, creando nuevos materiales o modificando procesos de producción que afectan al medio ambiente y a las personas y por tanto, generando nuevos peligros para la supervivencia humana.

La globalización, al incrementar la movilidad de mercancías y personas permite la transmisión de nuevas enfermedades y la reaparición de otras que se creían eliminadas en algunas regiones del planeta; pero, paradójicamente, el incremento del riesgo social va acompañado de una respuesta cada vez menor de la acción estatal para enfrentarlo. Si bien es cierto que la ciencia ofrece respuestas a muchos de los nuevos peligros de la vida moderna, los recursos de que se dispone sólo están en el mercado al alcance 
de un sector cada vez más reducido de la sociedad. Por lo tanto, se hace indispensable la intervención estatal para evitar que un número creciente de individuos se vean condenados a sufrir enfermedades o carencias a lo largo de su vida ante la dificultad de contar con recursos propios para sobrevivir.

La incidencia diferencial de los riesgos entre los grupos sociales en un país particular, se reproduce en el mundo entre países y no sólo son las condiciones naturales las que hacen que la población de algunas naciones esté expuesta a mayores peligros que otras, son las vulnerabilidades asociadas a condiciones socioeconómicas las que explican la existencia de mayores o menores riesgos entre las naciones.

Las catástrofes que en las décadas recientes se han producido con elevados costos en pérdidas humanas y materiales, muestran la vulnerabilidad de determinados sectores sociales, asociada tanto a la disponibilidad de recursos como a la ausencia de un marco normativo que disminuya su impacto. Las normas que deberían reducir la vulnerabilidad son inexistentes o no se cumplen, por incapacidad de las autoridades encargadas de vigilar su cumplimiento o de manera deliberada, para favorecer intereses particulares, a pesar de los efectos negativos que sus resultados puedan tener sobre la población.

En este escenario general, nuevos peligros aparecen y se universalizan, multiplicando sus efectos entre todos los grupos sociales por los procesos demográficos que se viven en la sociedad moderna.

La obligación del Estado de planear sus acciones con una visión estratégica para dar viabilidad a una sociedad, no lo exime de identificar los riesgos que pueden presentarse en el corto, mediano y largo plazo al diseñar una política pública, condición poco frecuente en el ámbito estatal y que, sin embargo, podría suponerse generalizada en las organizaciones del mercado; es decir, las empresas, para las cuales, la administración del riesgo debe formar parte de la visión gerencial, pero en la actual coyuntura no parece ser el caso ya que la sobrevivencia de una proporción significativa de éstas no está garantizada o cuando menos se percibe difícil, según lo muestran para México, los datos recientes de la Encuesta sobre el Impacto Económico Generado por Covid-19 en las Empresas (ECOVID-IE) 2020, realizada por el Instituto Nacional de Geografía y Estadística (INEGI).

En cualquier organización, la gestión de riesgos obliga a responder de manera sistemática a una serie de preguntas: ¿Qué sucede si ocurre un evento que ponga en riesgo la sobrevivencia de la organización?, ¿Qué probabilidad hay de que tal evento ocurra? y, ¿Cómo enfrentar tal evento para minimizar sus consecuencias negativas? 
Cómo es fácil observar, para responder a estas preguntas se requieren recursos que pueden ser clasificados en dos grupos: a) conocimiento y b) recursos materiales para enfrentar el evento.

Según la complejidad de la organización, el conocimiento puede demandar mayor especialización y un monto de recursos también mayor. En el caso de una organización como la familia, los eventos negativos están asociados a pérdidas materiales o humanas, relativamente sencillas de visualizar para un estudioso del tema, pero difíciles de identificar, o más específicamente, de aceptar, para sus miembros, porque es común la negación de su probable aparición ante la falta de recursos para enfrentarla. Lo que sucede en la familia cuando, ya sea que se visualizan o no los riesgos o no se está en capacidad de enfrentarlos, se ve amplificado en la sociedad. La respuesta organizacional a una pandemia como la Covid-19, es una muestra de la mala gestión del riesgo, tanto por falta de conocimientos como por falta de recursos.

En México, desde el inicio de la pandemia y durante varios meses, las autoridades de salud estuvieron insistiendo en que la población que presentara síntomas propios de las personas que hubieran sido contagiadas por el coronavirus SARS-CoV-2, se mantuvieran en sus hogares para no colapsar las clínicas y hospitales, sin haber aplicado pruebas para confirmar o descartar el contagio, lo que muestra de manera didáctica la mala gestión del riesgo, por desconocimiento y falta de recursos, en este caso, desconocimiento sobre la letalidad del virus, la escasa aplicación de pruebas y la limitada capacidad de atención hospitalaria.

Trasladada esta situación a nivel de la familia es evidente que los riesgos se multiplican ante la falta de conocimiento que los individuos tienen porque no son especialistas en salud, pero sobretodo, por la carencia de recursos, en un país en el cual una proporción importante de la población no tiene acceso a servicios de salud.

La Encuesta Nacional de Nutrición y Salud 2018, mostró, según la variable "Población total por condición de acceso a servicios médicos e institución", que uno de cada cinco mexicanos no está afiliado o cuenta con este tipo de servicios y lo más relevante es que, en el periodo de realización de la encuesta, el mayor porcentaje de la población afiliada a un servicio médico estaba cubierta por el Seguro Popular (37.4) y en las localidades de menos de 2,500 habitantes, este porcentaje era superior a $; 65$ por ciento!

La desaparición del Seguro Popular y su sustitución por el Instituto de Salud para el Bienestar (INSABI) a partir del 1 de enero de 2020 mediante el cual se pretende lograr la cobertura universal en servicio de salud y que 
en el Artículo $2^{\circ}$, al hacer referencia al derecho a la protección de la salud y sus finalidades, en su Fracción V, establece que esto significa: "Tratándose de personas que carezcan de seguridad social, la prestación gratuita de servicios de salud, medicamentos y demás insumos asociados" y en el Artículo 77 bis 1, que:

Todas las personas que se encuentren en el país que no cuenten con seguridad social tienen derecho a recibir de forma gratuita la prestación de servicios públicos de salud, medicamentos y demás insumos asociados, al momento de requerir la atención, de conformidad con el artículo 4o. de la Constitución Política de los Estados Unidos Mexicanos, sin importar su condición social (Artículo 77 bis 2).

Ésta, sin duda, ha sido una buena iniciativa que se instrumenta, a través del INSABI, de tal manera que,

La Secretaría de Salud, con el auxilio del Instituto de Salud para el Bienestar, organizará las acciones para la prestación gratuita de los servicios de salud, medicamentos y demás insumos asociados que requieran las personas sin seguridad social, cuando así lo haya pactado con las entidades federativas mediante la celebración de los acuerdos de coordinación (Artículo 77 bis 2).

En línea con las ideas previas, la necesidad de dar cobertura universal a la población sin seguridad social muestra que se reconocen los riesgos que enfrentan las personas en esta condición y se genera una respuesta institucional para enfrentarlos; sin embargo, no es suficiente con su reconocimiento si no se tienen los recursos organizacionales y económicos para cumplir con esta tarea.

En la práctica, ante la Covid-19, la limitación de recursos para atender a la población estaría detrás de la decisión de mantener en su hogar a quien tuviera síntomas de estar contagiado y evitar que asistiera a un centro de salud y de no realizar pruebas de detección temprana, que harían evidente el desequilibrio extremo entre demanda y oferta de servicios médicos, como efectivamente sucedió. El reconocimiento de esta situación objetiva, explica también que el índice para determinar el "Semáforo de Riesgo Epidemiológico Covid-19" en las entidades federativas, originalmente integrado por cuatro componentes, con igual peso en la conformación del índice (25 por ciento), le otorgó a partir de junio de 2020, el mayor peso a uno de sus componentes, el denominado Ocupación Hospitalaria de la Red IRAG (Red de Infección Respiratoria Aguda Grave) a quien se le asignó 50 
por ciento de ponderación. ${ }^{4}$ Los otros tres componentes del índice original y sus respectivas ponderaciones son: i) porcentaje de positividad al coronavirus, calculado con base en el número de pruebas realizadas en la semana epidemiológica analizada, diez por ciento; ii) tendencia de casos hospitalizados, derivado del número de personas que ingresan a un hospital por Covid-19, 20 por ciento y, iii), Tendencia del síndrome Covid-19, según la elevación o disminución del número de casos sospechosos registrados, 20 por ciento.

Lo descrito en el párrafo anterior muestra como la percepción del riesgo se modifica con la evolución del peligro y el reconocimiento de la vulnerabilidad asociada a los recursos disponibles, como lo reconoce el funcionario encargado de encabezar las acciones para enfrentarlo. Al decir que la ocupación hospitalaria representa "la mitad de la calificación", "porque es la capacidad que tiene cada estado para dar respuesta a los casos graves que se estén diagnosticando en sus estados". 5

\section{La Relación entre Demografía y SALUd PÚBLICA}

Para abordar problemas de salud pública, la demografía y el análisis institucional, son herramientas para tomar decisiones que fundamenten políticas y programas que pretendan incidir sobre el bienestar de la población.

Entre los factores que afectan directamente el estado de salud de una población se encuentran las condiciones demográficas, la estructura de los hogares y los arreglos familiares.

Aunque la relación entre las condiciones demográficas y el estado de salud de la población parece obvia, no necesariamente se reconoce al enfrentar problemas de salud de los seres humanos y se deja de lado el papel de la estructura social y los factores que la integran para comprender la génesis de muchas enfermedades y su incidencia diferencial entre grupos poblacionales a través del tiempo.

En el caso de México, una de las transformaciones más importantes en su demografía, se produce en la distribución por edad de su población y que se gesta a partir de los años 40 del siglo pasado, y se acelera en la segunda mitad del mismo. Este proceso, que en los países desarrollados se produce en periodos extremadamente largos, en México transcurre en tan sólo unas décadas y da lugar a un envejecimiento poblacional que obliga a la transformación de las instituciones que deben responder a las demandas

\footnotetext{
${ }^{4}$ Conferencia de prensa. Informe diario sobre coronavirus Covid-19 en México. Versión estenográfica. Presidencia de la República 12 de junio de 2020.

5 Dr. Hugo López Gatell. Informe diario sobre coronavirus Covid-19 en México. Versión estenográfica. Presidencia de la República 12 de junio de 2020.12 de junio de 2020.
} 
de una población en la que las personas de edad avanzada constituyen una proporción en crecimiento y que no se produce por la velocidad del cambio y por incapacidad.

Identificar los factores que han dado origen a los cambios poblacionales, permite comprender la manera en que el papel de las instituciones impacta el estado de salud de los individuos, a través de su incidencia en la transformación las condiciones materiales de su existencia, los hábitos de higiene, el cuidado de la salud en el espacio familiar, en la escuela y en el trabajo, el comportamiento sexual y reproductivo que incorpora la anticoncepción moderna y la oferta de servicios de cuidado de la salud en los sectores público, privado y social. Pero al mismo tiempo, el incremento de la sobrevivencia, la disminución del tamaño de las familias, el crecimiento de los hogares unipersonales y la movilidad de la población demandan nuevos arreglos institucionales que respondan a una realidad en constante transformación en la que la tecnología de la información y comunicación juega un papel cada vez más relevante.

La historia de la humanidad muestra con claridad cómo la estructura social, es decir, la forma en que se organiza y que le permite responder colectivamente a sus necesidades, incide sobre su estado de salud. En el pasado, el efecto de los fenómenos naturales se reflejaba en elevados niveles de mortalidad, producto de las hambrunas y de situaciones climatológicas extremas que se presentaban de manera recurrente en muchas naciones, pero también debe reconocerse que desde que los seres humanos se organizaron en grupos que crecían en complejidad organizacional y en número de individuos, las enfermedades contagiosas fueron un riesgo para su sobrevivencia. Las epidemias constituyen eventos catastróficos que hasta el siglo XX modificaron la estructura demográfica de varios países, sin que hubiera capacidad de respuesta institucional ante estas situaciones, tanto por desconocimiento de los mecanismos de transmisión de las enfermedades como por falta de recursos para curarlas.

La observación de las etapas en que se produce un crecimiento de la población a tasas elevadas, muestra que los avances en el conocimiento médico, el establecimiento de hospitales, el incremento en la provisión de agua y medidas de higiene y mejoras en las condiciones de las viviendas, junto con el abatimiento de las crisis de subsistencia, explican la disminución de la mortalidad en el pasado, lo cual implica transformaciones en la estructura productiva de la sociedad que, sin embargo, ha sido insuficiente para generar condiciones de bienestar general ya que la morbilidad y mortalidad de la población sigue siendo un factor de diferenciación social. 
Es en el siglo XX cuando se reconocen situaciones de vulnerabilidad asociadas a las características socioeconómicas de los individuos y se identifican condicionantes de la probabilidad de sufrir una enfermedad, e incluso la muerte, como resultado de la interacción del individuo con el ambiente social del cual forma parte. Esto hace que, en la estrategia para incrementar la esperanza de vida y el bienestar individual, se incorporase una visión del bienestar colectivo.

La seguridad social, junto con las políticas públicas en materia de salud, constituyen la institucionalización de las acciones para enfrentar los riesgos que atentan contra la salud y la sobrevivencia de la población, con un objetivo que va más allá de la lucha en contra de las enfermedades, ya que se propone el bienestar integral y se considera un medio para garantizar la viabilidad de la sociedad.

$\mathrm{Al}$ observar a través de la historia como se ha producido el incremento de la sobrevivencia, es claro que éste ha sido el resultado del desarrollo de la ciencia y sus aplicaciones médicas y de la creación de un marco institucional y una estructura organizacional, que ha posibilitado el acceso de la población a servicios de salud.

Para la salud pública, una aproximación fructífera para identificar los determinantes sociales de la salud la constituye el análisis de los procesos demográficos que permite observar las modificaciones que en la dimensión espacial y temporal se producen en la población. Adquieren especial significación como factores del ambiente social relacionados con la salud de los seres humanos: i) el tamaño de la localidad de residencia, relacionada con la posibilidad de contar con acceso a servicios de salud en la propia localidad; ii) las características de la vivienda en cuanto a material usado en su construcción y la disponibilidad de servicios, entre los que sobresale el acceso al agua potable, al incidir sobre la exposición al riesgo de contraer determinadas enfermedades y iii) la estructura del hogar, su tamaño y su jefatura, que afectan el uso de recursos en el hogar y las decisiones relativas al cuidado de la salud de sus miembros. En cuanto a las características individuales que definen su inserción estructural se encuentran fundamentalmente: a) el nivel de escolaridad, b) la actividad económica y c) el origen racial o la pertenencia étnica.

Debe destacarse como factor determinante de las condiciones de salud de una población su nivel de escolaridad, pero en especial la escolaridad de la mujer. La modificación del estatus social de la mujer a lo largo de la historia de la humanidad, parece estar relacionado con el incremento de la sobrevivencia de mujeres y hombres. La escolaridad modifica el estatus 
de la mujer; por tanto, una vía fructífera para explicar las diferencias en la salud de la población según nivel de escolaridad, es incorporar el papel de la educación en la modificación del estatus de la mujer. Esto, porque las mujeres son las responsables de los cuidados de los hijos en casi todos las culturas humanas y por tanto su rol es fundamental en el incremento de su sobrevivencia.

En el análisis de los determinantes sociales de la salud asociados a las transformaciones demográficas, destacan los hábitos alimenticios que inciden sobre el estado nutricional de las personas y los estilos de vida que se relacionan con condiciones de riesgo para desarrollar algunas enfermedades, la disponibilidad de servicios sanitarios como agua potable, drenaje, recolección de basura y el acceso a servicios de salud que actúan de manera preventiva o curativa y que incluyen la protección a las enfermedades a través de la vacunación, servicios de consulta médica y hospitalarios y adquisición de medicamentos.

Estos factores sociales, además de estar relacionados con la disponibilidad de recursos a nivel de la comunidad, interactúan con los efectos de las transformaciones demográficas que determinan la distribución y dispersión de la población y los arreglos domésticos en los hogares, que, a partir de la disponibilidad de recursos, el tamaño medio de las familias y las características individuales de sus miembros, inciden sobre la salud de la población. La simple existencia de servicios de salud no asegura el acceso a ellos; el rol de las instituciones es fundamental y esto incluye a la familia.

No sólo la medicina ha tenido un papel relevante en la disminución de la mortalidad en el mundo, también lo han sido los gobiernos que, a través de decisiones políticas para promover medidas de salud pública, multiplicaron los efectos de la aplicación de acciones curativas para abatir las enfermedades. En México, la creación del Instituto Mexicano del Seguro Social y las campañas implementadas por la Secretaría de Salubridad y Asistencia para abatir enfermedades como el paludismo son un claro ejemplo.

En este proceso, junto con las transformaciones estructurales, un aspecto relevante de la modernización al que contribuye la ciencia médica es el que hace que los individuos abandonen actitudes fatalistas, o de conformidad, que los llevan a pensar que si una persona se enferma o está en peligro de morir es porque "Dios quiere" o que la probabilidad de sufrir una enfermedad disminuye por usar amuletos que actúan como escudo protector.

Además, en el caso de las condiciones de salud de las poblaciones humanas, la movilidad espacial de la población constituye un aspecto fun- 
damental, que debe ser considerado en las acciones para protegerla. Es claro, en la coyuntura actual, que la movilidad espacial de la población, se convierte en un factor que incide no sólo en la transmisión de enfermedades, así la incorporación del migrante a la sociedad que lo recibe, tiene consecuencias sobre su estilo de vida y la forma en que se inserta en la estructura social, tiene efectos sobre su propia salud y la de las personas que le rodean.

Esta pandemia ha mostrado que la migración resulta ser un factor cada vez más relacionado con los determinantes de la salud porque, aunque las personas que migran generalmente tienen mejores condiciones de salud, cualquier persona que viaja es un potencial vector de transmisión de una enfermedad viral.

\section{EL CONOCIMIENTO DEMOGRÁFICO PARA DAR UNA RESPUESTA NO FARMACOLÓGICA A UNA PANDEMIA}

En México, la declaración del funcionario gubernamental encargado de coordinar las acciones para enfrentar la pandemia producida por el virus SARS-CoV-2, hecha en una de sus conferencias de prensa que diariamente se realizaron desde el mes de marzo de 2020, expresa con toda claridad lo que representa la respuesta no farmacológica a este evento y permite analizar cada uno de las condiciones a las que se verá enfrentada esta respuesta, a partir de una serie de características de la población ubicada en las viviendas en las que residen, los hogares que conforman y los roles que les toca desempeñar en aspectos sustantivos de la vida cotidiana y que incluso, pueden incidir en el mayor o menor éxito de esta estrategia.

Cuando entramos a una pandemia como ésta, a una situación extraordinaria no previsible, es una enfermedad emergente, genuinamente emergente, nos encontramos con un dilema, la manera de controlar la epidemia es mediante acciones que reducen la movilidad en el espacio público, la manera más efectiva conocida para mitigar, es decir, reducir los contagios de una enfermedad infecciosa de interés epidemiológico como es Covid-19. Esto, habida cuenta que no existen, ni tratamientos, ni vacunas, ni otros recursos que puedan modificar el curso de la epidemia, el único instrumento o conjunto de instrumentos para modificar el curso de la epidemia consiste en reducir la movilidad (énfasis añadido). Para reducir la movilidad se toman una serie de disposiciones por parte de la autoridad sanitaria que en el caso mexicano le llamamos la sana distancia...y que implican la suspensión temporal de actividades laborales que no sean esenciales, la suspensión temporal de actividades escolares y la sus- 
pensión de congregaciones en espacio público, que son los tres elementos que motivan mayormente a las personas a salir de casa. ${ }^{6}$

Con esto se reconoce que la propagación del virus y la afectación que produce sobre la salud no sólo depende de condiciones biológicas, también de la conducta de la población y de la respuesta a las recomendaciones de la autoridad sanitaria que pueden seguirse o ignorarse, dependiendo de diversos factores como el tipo de mensaje que transmite la autoridad, la conciencia de la gravedad del problema, la confianza que se tenga en el mensaje y en su emisor, y el costo que representa la inmovilidad, es decir, "quedarse en casa" o "guardar la sana distancia" y que puede ser claramente diferencial entre grupos sociales según sus características sociodemográficas.

Parece evidente que en el caso de México hemos tenido un claro ejemplo de lo que se puede hacer y lo que no se puede hacer, pero también de lo que se debe hacer y de lo que no se debe hacer. En el primer caso, las palabras del Dr. López Gatell lo ilustran:

Si sólo existiera la epidemia de Covid-19 y nada más, lo idóneo sería seguirse (sic) en confinamiento por meses hasta que posiblemente no existiera un solo caso en el mundo, pero eso sería quizá un par de años. En el otro lado hay que reactivar la vida pública incluyendo que las personas que viven al día tengan ingresos, que se active el país por todas las razones del bienestar".7

Lo que se debe o no se debe hacerse, esto se observa en las acciones tardías de detección de las personas contagiadas y no aplicar las pruebas en forma masiva y también en la generación de mensajes contradictorios que, entre otras cosas, ignoraron las recomendaciones de agencias internacionales para usar el cubreboca aunque había evidencias científicas de su efectividad a nivel internacional (ver, por ejemplo, Brienen and Teunis, 2010); incluso, las experiencias que se vivieron en México en años recientes, como es el caso de la epidemia por una mutación del virus de la influenza (A H1N1) mostraron su efectividad.

Además, una decisión errónea cada vez más evidente, ha sido obligar a la población que presenta síntomas de enfermedad causada por el virus SARS-CoV-2 a permanecer en su casa para no saturar las instalaciones hospitalarias, lo que ha provocado que, en muchos casos, las personas en-

${ }^{6}$ Dr. Hugo López Gatell. Subsecretario de Prevención y Promoción de la Salud. Secretaría de Salud, México. Reporte diario de coronavirus, 13 de mayo de 2020. Transcripción de la grabación original. Puntuación agregada.

7 Dr. Hugo López Gatell. Subsecretario de Prevención y Promoción de la Salud. Secretaría de Salud, México. Reporte diario de coronavirus, 27 de mayo de 2020. Versión estenográfica. 
fermas lleguen de forma tardía a recibir los tratamientos disponibles y la enfermedad tenga consecuencias fatales.

Las decisiones de política pública, deben basarse cada vez más en el conocimiento científico y el político debe ser asesorado por especialistas que tengan la capacidad de ser "identificadores de riesgos" para disminuir la probabilidad de que se presente "una situación extraordinaria no previsible," para usar el lenguaje del funcionario citado en un párrafo previo.

Es indispensable adelantarse a los acontecimientos y una vez que se presentan, las acciones para enfrentarlos deberán considerar las condiciones objetivas de la población.

\section{Mortalidad, SU EFECTO Visible}

Por ser su efecto extremo, la cantidad extraordinaria de defunciones provocadas por el virus SARS-CoV-2 ha estado en el centro de la atención pública, pero el proceso que lleva a este desenlace y sobre el cual deben actuar los especialistas para evitarlo, ha estado sujeto a decisiones políticas que pueden haber tenido efectos en su incidencia y su letalidad y que sólo será posible estimar con el paso del tiempo y con mayor conocimiento de su evolución y sus determinantes, porque hasta el momento de la redacción de este texto, la información sobre las muertes directamente asociadas con los efectos de este virus no se conoce con precisión.

Hasta el 31 de diciembre del año 2020, la cifra oficial de defunciones en México es de 125,807 y estas "defunciones totales de Covid-19,... se integran por: defunciones confirmadas a SARS-CoV-2 por laboratorio... y defunciones por asociación o dictaminación clínica-epidemiológica", según lo dispuesto por la Secretaría de Salud a partir del 5 de octubre de $2020 .{ }^{8} \mathrm{Al}$ sumar otro grupo significativo de defunciones que parecen asociadas a los efectos de este virus, pero que estaban "en espera de resultados de una prueba PCR y/o casos sospechosos", sin contar con las pruebas que lo confirmen se estimaban un total de 17,762.

Especialistas nacionales y organizaciones internacionales consideran que esta cifra subestima el verdadero número de defunciones asociadas al virus porque, aunque se hayan considerado casos asociados o que se atribuyen a esta causa, hay un número desconocido de muertes de personas que fallecieron sin haber pasado por un dictamen que identificara al virus y sus efectos como causa de la muerte (Hernández, 2020; OMS, 2020%).

\footnotetext{
${ }^{8}$ Informe Técnico Diario Covid-19 México, 05/10/2020. Secretaría de Salud. Subsecretaría de Prevención y Promoción de la Salud. México.

${ }_{9}$ https://www.who.int/es/home
} 
Con las limitaciones derivadas de un probable registro incompleto de las defunciones, las bases de datos que la Dirección General de Epidemiología ha puesto a disposición del público, ${ }^{10}$ permiten conocer el perfil de las personas cuya muerte está asociada con el virus SARS-CoV-2.

\section{ESTRUCTURAS DEMOGRÁFICAS BÁSICAS}

El análisis de la estructura de las defunciones según algunas de sus características, nos obliga a conocer las estructuras demográficas básicas de la sociedad y los factores que pueden generar situaciones de vulnerabilidad ante una pandemia como la Covid-19 para implementar acciones que limiten su impacto.

\section{Estructura por edad}

Para la demografía, la estructura por edad de una población está asociada a las condiciones de vulnerabilidad; simplemente, porque las personas de edad avanzada suman diversos factores que contribuyen a multiplicarla debido a condiciones de salud que se modifican con el paso del tiempo y que, ante una emergencia sanitaria, las dejan en la indefensión.

El proceso de envejecimiento es observable en un gran número de países por la proporción o porcentaje que ocupa la población de 70 o más años de edad, con respecto al total. En Japón, representa 22 por ciento, en Alemania 16 por ciento, en Francia 15 por ciento, en Uruguay 10.8 por ciento y en México cinco por ciento.

Una de las primeras reacciones de los especialistas ante la aparición de la pandemia en los países europeos, fue que el riesgo de muerte estaba asociado a la edad avanzada de quienes habían sido infectados por el virus, debido a la existencia de enfermedades crónicas que los hace susceptibles de llegar a condiciones severas que requieran hospitalización y aumenten el riesgo de muerte. Esto, encendió la alarma en Europa y generalizó la idea inicial de que la pandemia se cebaría en los países más envejecidos.

El Centro Chino para el Control y Prevención de las Enfermedades (CDC) con datos que van de diciembre de 2019 a febrero de 2020, mostró que poco más de 80 por ciento de las defunciones de casos confirmados de Covid-19 en China, lo constituían personas de 60 o más años y, ya que se captó la actividad de las personas que fallecieron, se concluyó que 74 por ciento eran "retirados". ${ }^{11}$ La difusión de este análisis generó la imagen

$10 \mathrm{https}: / / w w w . g o b . \mathrm{mx} / \mathrm{salud} /$ documentos/datos-abiertos

11 Este porcentaje se obtiene de aquellos casos en los que se captó con precisión su actividad ya que para 37 por ciento del total de defunciones Covid-19, no se pudo determinar este dato. Ver la 
primigenia de una enfermedad mortal para los viejos, ya que la tasa de letalidad de este grupo (que llegó a 14.8 por ciento para el grupo 80 o más) era claramente superior al de la población más joven que no llegaba al uno por ciento.

La situación fue aún más grave para la población de edad avanzada en otros países, en España en el mes de marzo de 2020, según datos del Ministerio de Sanidad, 87 por ciento de los fallecidos tenía 70 o más años de edad, dos meses después (mayo) este porcentaje no se había modificado, ${ }^{12}$ esto confirmaba la idea de expertos como Ignacio Rosell de la Universidad de Valladolid, de que: "los datos indican que tener una población tan envejecida como la española puede ser el hecho que mejor explica las cifras de casos graves y de muerte". ${ }^{13}$

En Italia, a mediados del mes de marzo, 89 por ciento de las defunciones acumuladas correspondieron a personas de 70 o más años de edad. ${ }^{14} \mathrm{En}$ Alemania, al 29 de marzo, el 88 por ciento de las defunciones acumuladas asociadas a Covid-19 era de personas en este grupo de edad. Para finalizar el mes de septiembre esta cifra se mantuvo prácticamente sin cambio en 85 por ciento. ${ }^{15}$

En los Estados Unidos, según el Centro para el Control de Enfermedades (CDC), "el riesgo de enfermarse gravemente a causa del Covid-19 aumenta a medida que se envejece" y, ya avanzada la pandemia, en el mes de septiembre, se estimó que ocho de cada diez defunciones originadas por este virus han sido de personas con 65 o más años de edad. ${ }^{16}$ Este perfil etario de las defunciones parece estar relacionado como ya se mencionó, con la preexistencia de comorbilidades, de lo cual se hablará en otro apartado del texto.

En Chile las defunciones asociadas a Covid-19 (confirmadas y sospechosas), de personas de 70 años o más al 29 de octubre de 2020 representaron 64 por ciento del total. ${ }^{17}$

cita, CDC. 2020, en la bibliografía.

${ }^{12}$ Hasta el 18 de mayo de 2020, el Ministerio de Sanidad publicó la información que permite conocer las características demográficas de contagiados, hospitalizados, ingresados a UCI y fallecidos.

${ }_{13}$ Entrevista a Ignacio Rosell para El Confidencial. https://www.elconfidencial.com/tecnologia/2020-03-25/coronavirus-espana-fallecidos-edad-italia_2516359/

${ }_{14}$ Italian National Institute of Health (Istituto superiore di sanità - ISS); Disponible en https:// www.epicentro.iss.it/coronavirus/

${ }^{15}$ German Data Files Archives, en poder de los autores de este texto provistos por el Robert Koch Institute.

${ }^{16}$ Cdc.gov/coronavirus.

17 Análisis propio de las bases de datos del Ministerio de Salud de Chile y que están ya disponibles en https://www.minsal.cl/nuevo-coronavirus-2019-ncov/casos-confirmados-en-chile-covid-19/. 
En México, en la etapa inicial de la pandemia y concretamente al finalizar el mes de abril, las defunciones asociadas a Covid-19, de personas de 70 o más años representaron 24 por ciento y al 31 de diciembre de 2020 , 34 por ciento, según los datos de la Tabla 1. Esto muestra que la mortalidad por coronavirus a diferencia de lo que sucede en otros países, afecta en porcentajes significativos a la población en edades productivas, población que aún tiene responsabilidades centrales como jefe de familia y sostén económico de la misma.

Tabla 1: México. Distribución porcentual de defunciones con diagnóstico positivo por SARS-CoV-2, en dos fechas sucesivas

\begin{tabular}{lrr}
\hline Grupos de edad & \multicolumn{2}{l}{ Fecha } \\
& $30 / 04 / 2020$ & $31 / 12 / 2020$ \\
\hline 0 a 9 & 0.3 & 0.2 \\
10 a 19 & 0.1 & 0.2 \\
20 a 39 & 7.9 & 5.1 \\
40 a 54 & 29.7 & 20.3 \\
55 a 69 & 38.4 & 40.0 \\
70 o más & 23.7 & 34.2 \\
Total & 100.0 & 100.0 \\
\hline Fuente: elaboración propia a partir de la base de datos abiertos de Covid-19. Dirección General \\
de Epidemiología. Secretaría de Salud. Disponible en: https://www.gob.mx/salud/documentos/da- \\
tos-abiertos-152127.
\end{tabular}

Sin embargo, debe observarse que la tasa de letalidad por edad de los enfermos registrados en la base de datos de la Dirección General de Epidemiología de la Secretaría de Salud, (con excepción de la cifra del grupo de cero a cuatro años) se va incrementando de manera significativa junto con la edad de las personas, hasta superar al 40 por ciento en el caso de la población masculina a partir de los 75 años, según se puede ver en la Tabla 2.

Una serie de factores inciden sobre la importante participación de este grupo en la mortalidad total, que pueden clasificarse en dos grupos según el tipo de riesgo que originan: biológicos y sociodemográficos. En el primer grupo, encontramos las condiciones de salud asociadas a las enfermedades previas que hacen más vulnerables a los individuos y que en México muestran ya una prevalencia importante desde edades jóvenes como se mostrará más adelante. Los factores sociodemográficos representan las condiciones en que viven y las actividades a través de las cuales sobreviven las personas. 
Tabla 2: México. Tasa de letalidad por edad y sexo de pacientes positivos SARS-CoV-2 al 31 de diciembre de 2020 (\%)

\begin{tabular}{lccr}
\hline Grupo de edad & Mujeres & Hombres & Total \\
\hline 0 a 4 & 2.84 & 3.07 & 2.96 \\
5 a 9 & 0.36 & 0.72 & 0.55 \\
10 a 14 & 0.34 & 0.47 & 0.40 \\
15 a 19 & 0.42 & 0.38 & 0.40 \\
20 a 24 & 0.39 & 0.60 & 0.49 \\
25 a 29 & 0.47 & 0.88 & 0.67 \\
30 a 34 & 0.78 & 1.64 & 1.20 \\
35 a 39 & 1.17 & 2.76 & 1.97 \\
40 a 44 & 2.16 & 5.02 & 3.59 \\
45 a 49 & 3.66 & 7.94 & 5.79 \\
50 a 54 & 5.89 & 11.75 & 8.83 \\
55 a 59 & 9.98 & 16.99 & 13.60 \\
60 a 64 & 16.13 & 24.05 & 20.30 \\
65 a 69 & 22.67 & 31.44 & 27.42 \\
70 a 74 & 29.12 & 37.98 & 34.02 \\
75 a 79 & 33.53 & 42.28 & 38.36 \\
80 a 84 & 37.88 & 47.29 & 43.06 \\
85 o más & 37.88 & 48.74 & 43.63 \\
Total & 6.51 & 11.10 & 8.82 \\
\hline Fuente: elaboración propia a partir de la base de datos abiertos de Covid-19. Dirección General \\
de Epidemiología. Secretaría de Salud. Disponible en: https://www.gob.mx/salud/documentos/da- \\
tos-abiertos-152127 & & & \\
\end{tabular}

Ante una respuesta no farmacológica a la pandemia, la población joven, tiene un mayor riesgo de contagio ante la imposibilidad de permanecer en su casa. Es obvio que la necesidad de generar ingresos obliga a este grupo a salir a trabajar, e interactuar con otras personas en los medios de transporte colectivo y en los lugares de trabajo, pero también creemos que al principio de la pandemia, la socialización de la idea de que el virus sólo era mortal entre los viejos y no afectaría a los pobres, hizo que la población de adultos jóvenes y adultos de edad madura, no tuviera cuidado para evitar el contagio. 
Desde nuestra perspectiva, más allá de condiciones biológicas que incrementan el riesgo de muerte, existen otros factores de naturaleza social que explicarían el mayor riesgo de muerte entre los viejos. Como apunta Lima-Acosta (2020)

existen implicaciones diversas de la epidemia para las franjas etarias de mayor edad. La primera de ellas es la discriminación por edad... que se traduce en el estereotipo, perjuicio y discriminación contra las personas más viejas. Esta concepción inaceptable puede llevar a la "naturalización" de la pérdida de vidas entre los más viejos, implicando condiciones diferenciadas de apoyo social, tratamiento y medidas de prevención.

Aunque, ante la severidad de la pandemia por su incidencia y letalidad, las autoridades sanitarias se ven en la necesidad de definir procesos de triaje para la atención de los pacientes en estado crítico como medida para la asignación de recursos a partir de consideraciones éticas, esto es motivo de controversia permanente.

El Consejo de Salubridad General publicó la Guía de Bioética de Asignación de Recursos de Medicina Crítica, con los criterios que debe considerar el personal médico precisamente, como lo dice el título de esta Guía, en la asignación de recursos para atender a las personas cuando la capacidad en las áreas de cuidados críticos se vea rebasada o esté cerca de llegar a esta condición.

Para los objetivos de este texto, vale la pena citar algunos conceptos fundamentales que se incluyen en esta Guía y resultan fundamentales para las políticas públicas y las acciones en materia de salud: "En la práctica médica cotidiana el objetivo primordial es prevenir, tratar o curar las enfermedades o padecimientos de un paciente concreto. Los principios bioéticos relevantes para dicha práctica médica son los de autonomía, beneficencia, no maleficencia y justicia. En la práctica de salud pública el objetivo primordial es que la salud de la población sea la mejor posible de acuerdo a la cantidad de recursos disponibles. El principio que generalmente se considera que gobierna a la salud pública es el de la justicia social. He aquí un ejemplo de posible conflicto entre estas dos disciplinas: un(a) médico(a) puede considerar que cierta vacuna es benéfica para determinado paciente, mientras que el mismo médico(a), como oficial de la salud pública, puede considerar que dicho paciente, al no estar dentro de un grupo de riesgo, no la debería recibir por tratarse de un recurso escaso" (Guía: 3 ).

Este ejemplo de recomendaciones, es de gran actualidad ante la disponibilidad limitada en el corto plazo de una serie de vacunas para evitar la 
enfermedad multicitada que obligan a decidir quiénes deben recibirla en primera instancia.

Un principio fundamental en esta materia es que, ante recursos escasos, la decisión es asignarlos hacia quien se considera que tiene mayores probabilidades de sobrevivir, por tanto, es común que la edad del paciente se considere un factor asociado a estas probabilidades.

Ya que, en México, pero también en otros países, un objetivo fundamental de las acciones iniciales para enfrentar la pandemia fue evitar que los hospitales se colapsaran y que las personas con síntomas de la enfermedad se quedaran en su casa, los viejos parecían ser el "grupo desechable".

Para los familiares o las personas cercanas a un enfermo en estado crítico, otorgarle atención está fuera de toda discusión, a menos que se encuentre en estado terminal y no haya posibilidad de revertirlo y se considere que prolongar su vida es sólo prolongar su sufrimiento; sin embargo, en un entorno de recursos escasos la decisión al respecto trata de incorporar criterios objetivos, que no necesariamente son de comprensión general y sí en cambio, pueden justificar acciones que, cuando menos, pueden ser discutibles desde el punto de vista ético.

Los ejemplos de decisiones que parecen haber tenido como único objetivo evitar que se colapsaran los servicios de salud son didácticos y como muestra, se cita uno de ellos a continuación que hace referencia al entorno internacional.

En la Comunidad de Madrid, una investigación del periódico El País, documentó la decisión de excluir a los ancianos de recibir atención médica simplemente por el hecho de serlo.

"Carlos Mur de Víu, director de coordinación sociosanitaria, envió al menos cuatro correos a la Consejería de Políticas Sociales pidiendo dar traslado de los protocolos de triaje,... el fin era evitar el colapso de la sanidad madrileña... según múltiples testimonios de familiares de fallecidos en residencias, las negativas fueron casi generalizadas en el período más crítico de la pandemia, entre mitad de marzo y mitad de abril. Algunos familiares e incluso una directiva de una cadena de residencias han asegurado que se llegó a descartar únicamente con el criterio de la edad avanzada de los enfermos". ${ }^{18}$

Ya que, en este caso, parecería que los viejos serían los desechables, también, desde el sector privado en España, se consideró que los viejos constituían un obstáculo para avanzar en el desconfinamiento y la reapertura de actividades, de tal manera que la patronal de Valladolid, a través de

18 El País, La Comunidad de Madrid envió al menos cuatro correos para excluir de hospitales a ancianos de residencias. Junio 9 de 2020. Nota firmada por Fernando Peinado. 
su página oficial emitió un comunicado que entre otras ideas expresaba:

Desde CVE (Confederación Vallisoletana de Empresarios) nos preguntamos cómo quedaría la tasa de enfermos de las diferentes áreas de salud si en su cálculo se excluyeran los datos de focos de riesgo como pueden ser las residencias de ancianos puesto que no es sociedad productiva que vaya a incorporarse a puestos de trabajo. Del análisis de los datos que proporciona la Junta de Castilla y León, CVE tiene la sospecha de que el número de fallecidos por Covid-19 en residencias son los que están provocando que los datos de las áreas de salud estén por encima del criterio que se ha marcado la Junta de Castilla y León (para la reapertura). ${ }^{19}$

¿Es posible que la caracterización de la Covid-19 como una pandemia que afecta fundamentalmente a las personas de edad avanzada, explique el descontrol inicial por enfrentarla debidamente? Esta es una pregunta que aplica para todos los países, incluyendo a México.

\section{Morbilidad. Perfil de morbilidad por edad}

Sobre los factores biológicos y los factores sociales que inciden en la salud de los individuos, pueden incidir las políticas públicas, aunque es probable que sus efectos difieran en el tiempo en que pueden consolidarse por la naturaleza de sus orígenes; además, la interacción entre biología y sociedad es un hecho objetivo.

La Organización Mundial de la Salud, ha reconocido que:

Cada vez hay más pruebas de que las personas con afecciones crónicas existentes o con sistemas inmunes comprometidos debido a una discapacidad del sistema inmunitario, tienen un mayor riesgo de muerte por Covid-19. Las condiciones crónicas pueden ser enfermedades no transmisibles como la enfermedad de las arterias coronarias, la enfermedad pulmonar obstructiva crónica (EPOC) y la diabetes o discapacidades (OPS, OMS, 2020: 4).

La cita previa confirma el conocimiento acumulado sobre la vulnerabilidad de la población que sufre el embate de una enfermedad infecciosa y que tiene además una enfermedad crónica y, por tanto, presenta un mayor riesgo de muerte (Murray y López, 1996; Lozano et al., 2007; Lozano et al., 2013; Wong et al., 2015).

Las evidencias de la estrecha relación entre la existencia de comorbilidades y riesgo de muerte entre los pacientes contagiados por SARS-CoV-2, ha vuelto a poner en circulación la idea de que la Covid-19 es más una sin-

19 Confederación Vallisoletana de Empresarios. https:/www.cve.es/cve/cve-pide-a-la-junta-decastilla-y-leon-sensibilidad-con-el-empleo-y-las-empresas-de-la-comunidad-autonoma/ 
demia que una pandemia, porque las condiciones de las personas enfermas son el resultado de la interacción de más de una enfermedad y por lo tanto, con el propósito de enfrentar sus consecuencias y en el extremo evitar la muerte de un individuo, se deben tomar medidas a través de las cuales se atiendan los padecimientos asociados preexistentes. En términos prácticos, esto significa que el combate a la Covid-19 tendrá resultados limitados si sólo se lucha contra el virus que la produce.

El sistema de información en salud, describe el perfil de la morbilidad de la población asociado a sus características demográficas como edad, sexo y lugar de residencia, datos indispensables para fundamentar programas en materia de salud pública y acciones concretas de prevención de enfermedades, por lo que el conocimiento de este panorama es fundamental en una coyuntura como la que el virus SARS-CoV-2 ha provocado.

Las principales enfermedades que afectan a la población en el país, se identifican en las tablas 3, 4 y 5, en los que se han listado los 20 principales padecimientos en México en tres cortes transversales correspondientes a los años 2000, 2010 y 2019.

Como era posible esperar, las enfermedades causadas por agentes patógenos ocupan los primeros lugares por su incidencia, ya sean éstas infecciones respiratorias agudas, infecciones intestinales o infecciones de vías urinarias, pero en este listado debe destacarse la presencia de enfermedades crónico-degenerativas como la diabetes mellitus o la hipertensión arterial y aparece también la obesidad en un lugar importante, lo que justifica la atención que se ha puesto en años recientes a ciertos padecimientos, las campañas para detectarlos y las medidas de salud pública para enfrentarlos. Es indudable que el perfil de morbilidad observado en estos cuadros, responde a factores biológicos y demográficos como el envejecimiento, pero también a estilos de vida que generan condiciones para su aparición, sobre los que es posible actuar desde distintos frentes en los cuales las acciones gubernamentales tienen un importante papel.

La información presentada en las tablas 3, 4 y 5, al estar basados en la notificación de casos nuevos tiene las limitaciones propias de un registro incompleto ya que sólo contabiliza los eventos reportados a través de los servicios médicos; sin embargo, ofrece un panorama que debería permitir al sistema de salud definir acciones primero, para incidir en la disminución de la morbilidad y, en la actual pandemia, responder a las condiciones de vulnerabilidad que de acuerdo con la información disponible, la incidencia de las enfermedades hace evidente. 
Tabla 3: Incidencia de las 20 principales enfermedades en la población por grupos de edad (por 100 mil). México 2000

\begin{tabular}{|c|c|c|c|c|c|c|c|}
\hline \multirow{2}{*}{ No. } & \multirow{2}{*}{ Padecimiento } & \multicolumn{6}{|c|}{ Grupos de edad } \\
\hline & & $<1$ & $1-4$ & $5-9$ & $10-14$ & $15-19$ & $20-24$ \\
\hline 1 & Infecciones respiratorias agudas & 171,111 & 80,502 & 37,795 & 22,844 & 14,675 & 16,631 \\
\hline 2 & $\begin{array}{l}\text { Infecciones intestinales } \\
\text { por otros organismos }\end{array}$ & 29,215 & 11,586 & 3,957 & 2,934 & 2,443 & 3,819 \\
\hline 3 & Infección de vías urinarias & 1,507 & 1,594 & 1,296 & 1,009 & 1,720 & 3,354 \\
\hline 4 & Amebiasis intestinal & 3,736 & 3,022 & 1,794 & 1,344 & 901 & 956 \\
\hline 5 & Úlceras, gastritis y duodenitis & 10 & 9 & 159 & 426 & 978 & 1,547 \\
\hline 6 & Otras helmintiasis & 1,194 & 1,705 & 1,167 & 873 & 487 & 527 \\
\hline 7 & Otitis media aguda & 1,547 & 1,321 & 1,039 & 635 & 413 & 418 \\
\hline 8 & Hipertensión arterial & 1 & 1 & 1 & 3 & 14 & 63 \\
\hline 9 & Varicela & 1,036 & 1,064 & 893 & 455 & 310 & 350 \\
\hline 10 & Ascariasis & 271 & 1,099 & 874 & 492 & 206 & 151 \\
\hline 11 & Candidiasis urogenital & 29 & 14 & 13 & 30 & 203 & 574 \\
\hline 12 & Diabetes mellitus & 0 & 0 & 0 & 0 & 0 & 39 \\
\hline 13 & Asma & 35 & 595 & 380 & 239 & 124 & 140 \\
\hline 14 & Insuficiencia venosa periférica & 0 & 1 & 0 & 1 & 41 & 151 \\
\hline 15 & Desnutrición leve & 1,649 & 1,674 & 235 & 121 & 28 & 14 \\
\hline 16 & Angina estreptocócica & 555 & 568 & 409 & 258 & 162 & 154 \\
\hline 17 & $\begin{array}{l}\text { Intoxicación por picadura } \\
\text { de alacrán }\end{array}$ & 129 & 240 & 223 & 241 & 229 & 216 \\
\hline 18 & Neumonías y bronconeumonías & 2,216 & 575 & 133 & 70 & 48 & 58 \\
\hline 19 & Tricomoniasis urogenital & 0 & 0 & 0 & 14 & 113 & 340 \\
\hline 20 & Conjuntivitis mucopurulenta & 762 & 288 & 183 & 129 & 97 & 101 \\
\hline
\end{tabular}

Fuente: elaboración propia con datos de Anuarios de Morbilidad 1984-2019, Dirección General de Epidemiología, Secretaría de Salud. Disponible en: https:/epidemiologia.salud.gob.mx/anuario/ $\mathrm{html} /$ anuarios.html

Además del conocimiento de la incidencia de las enfermedades sobre la población del país que los registros epidemiológicos hacen posible, el sistema de salud en México ha puesto en funcionamiento un conjunto de encuestas sero-epidemiológicas, que iniciaron con la Encuesta Nacional de Salud desde los años 90 del siglo XX y que se ha mantenido hasta la fecha para conocer la prevalencia de ciertas enfermedades. 
Conocimiento sociodemográfico y respuesta institucional a una pandemia. El caso de México / C. WELTI y A.C. RAMÍREZ

Tabla 3: Continuación

\begin{tabular}{|c|c|c|c|c|c|c|}
\hline \multirow{2}{*}{ No. } & \multirow{2}{*}{ Padecimiento } & \multicolumn{5}{|c|}{ Grupos de edad } \\
\hline & & $25-44$ & $45-49$ & $50-59$ & $60-64$ & $650+$ \\
\hline 1 & Infecciones respiratorias agudas & 17,667 & 22,958 & 20,305 & 24,140 & 19,393 \\
\hline 2 & $\begin{array}{l}\text { Infecciones intestinales por otros } \\
\text { organismos }\end{array}$ & 4,308 & 5,326 & 4,936 & 5,831 & 5,446 \\
\hline 3 & Infección de vías urinarias & 3,907 & 5,222 & 4,825 & 5,657 & 5,243 \\
\hline 4 & Amebiasis intestinal & 915 & 1,326 & 1,084 & 1,345 & 1,110 \\
\hline 5 & Úlceras, gastritis y duodenitis & 1,743 & 2,702 & 2,440 & 2,995 & 2,643 \\
\hline 6 & Otras helmintiasis & 474 & 531 & 519 & 604 & 518 \\
\hline 7 & Otitis media aguda & 392 & 615 & 416 & 509 & 375 \\
\hline 8 & Hipertensión arterial & 312 & 1,390 & 1,576 & 2,344 & 2,021 \\
\hline 9 & Varicela & 141 & 26 & 16 & 15 & 19 \\
\hline 10 & Ascariasis & 116 & 190 & 125 & 167 & 112 \\
\hline 11 & Candidiasis urogenital & 566 & 632 & 276 & 211 & 102 \\
\hline 12 & Diabetes mellitus & 219 & 1,092 & 1,266 & 1,771 & 1,210 \\
\hline 13 & Asma & 186 & 320 & 308 & 393 & 363 \\
\hline 14 & Insuficiencia venosa periférica & 333 & 633 & 669 & 784 & 674 \\
\hline 15 & Desnutrición leve & 8 & 14 & 10 & 16 & 23 \\
\hline 16 & Angina estreptocócica & 132 & 192 & 119 & 144 & 88 \\
\hline 17 & $\begin{array}{l}\text { Intoxicación por picadura } \\
\text { de alacrán }\end{array}$ & 174 & 226 & 192 & 247 & 221 \\
\hline 18 & Neumonías y bronconeumonías & 73 & 157 & 167 & 332 & 603 \\
\hline 19 & Tricomoniasis urogenital & 338 & 385 & 147 & 98 & 38 \\
\hline 20 & Conjuntivitis mucopurulenta & 113 & 188 & 156 & 216 & 191 \\
\hline
\end{tabular}

Fuente: elaboración propia con datos de Anuarios de Morbilidad 1984-2019, Dirección General de Epidemiología, Secretaría de Salud. Disponible en: https:/epidemiologia.salud.gob.mx/anuario/ $\mathrm{html} /$ anuarios.html

Con este sistema de encuestas se tiene, por tanto, el conocimiento de la incidencia y prevalencia de las enfermedades, lo que debería obligar a actuar sobre éstas.

No hay, en México, desconocimiento que justifique la inacción o la acción mal fundada en materia de salud. La información sociodemográfica ha contribuido a la construcción de escenarios cada vez más detallados para tomar decisiones fundamentadas cuyo objetivo sea lograr el bienestar de la población a través de acciones públicas, con la contribución de cada uno de los sectores de la sociedad que tienen derechos, pero también obligaciones. 
Tabla 4: Incidencia de las 20 principales enfermedades en la población por grupos de edad (por 100 mil). México. 2010

\begin{tabular}{|c|c|c|c|c|c|c|c|}
\hline \multirow{2}{*}{ No. } & \multirow{2}{*}{ Padecimiento } & \multicolumn{6}{|c|}{ Grupos de edad } \\
\hline & & $<1$ & $1-4$ & $5-9$ & $10-14$ & $15-19$ & $20-24$ \\
\hline 1 & $\begin{array}{l}\text { Infecciones respiratorias } \\
\text { agudas }\end{array}$ & 138,479 & 81,671 & 40,159 & 22,925 & 15,259 & 15,166 \\
\hline 2 & $\begin{array}{l}\text { Infecciones intestinales } \\
\text { por otros organismos }\end{array}$ & 19,404 & 13,480 & 5,331 & 3,324 & 2,525 & 3,246 \\
\hline 3 & Infección de vías urinarias & 1,247 & 1,935 & 1,749 & 1,285 & 2,630 & 3,824 \\
\hline 4 & $\begin{array}{l}\text { Úlceras, gastritis } \\
\text { y duodenitis }\end{array}$ & N.A. & N.A. & N.A. & 742 & 1,225 & 1,623 \\
\hline 5 & Otitis media aguda & 1,244 & 1,455 & 1,073 & 638 & 476 & 462 \\
\hline 6 & $\begin{array}{l}\text { Gingivitis y enfermedades } \\
\text { periodontales }\end{array}$ & 45 & 163 & 381 & 392 & 552 & 645 \\
\hline 7 & Hipertensión arterial & N.A. & N.A. & N.A. & N.A. & 16 & 58 \\
\hline 8 & Conjuntivitis & 1,854 & 852 & 529 & 405 & 361 & 357 \\
\hline 9 & Amebiasis intestinal & 1,043 & 1,146 & 654 & 432 & 298 & 299 \\
\hline 10 & $\begin{array}{l}\text { Diabetes mellitus no } \\
\text { insulinodependiente }\end{array}$ & 1 & 1 & 1 & 2 & 7 & 35 \\
\hline 11 & Asma y estado asmático & 591 & 893 & 620 & 332 & 159 & 152 \\
\hline 12 & Otras helmintiasis & 204 & 748 & 584 & 351 & 193 & 177 \\
\hline 13 & Candidiasis urogenital & 16 & 9 & 10 & 29 & 240 & 545 \\
\hline 14 & $\begin{array}{l}\text { Intoxicación por picadura } \\
\text { de alacrán }\end{array}$ & 94 & 285 & 271 & 298 & 331 & 299 \\
\hline 15 & Varicela & 786 & 1,077 & 630 & 236 & 128 & 127 \\
\hline 16 & $\begin{array}{l}\text { Neumonías } \\
\text { y bronconeumonías }\end{array}$ & 1,434 & 452 & 97 & 46 & 30 & 38 \\
\hline 17 & Tricomoniasis urogenital & 1 & 2 & 3 & 8 & 99 & 234 \\
\hline 18 & Quemaduras & 103 & 178 & 76 & 69 & 84 & 134 \\
\hline 19 & $\begin{array}{l}\text { Paratifoidea y otras } \\
\text { salmonelosis }\end{array}$ & 26 & 44 & 69 & 99 & 117 & 131 \\
\hline 20 & Desnutrición leve & 1,133 & 787 & 174 & 78 & 35 & 18 \\
\hline
\end{tabular}

Fuente: Secretaría de Salud, Dirección General de Epidemiología, Anuarios de Morbilidad 19842019. Disponible en https://epidemiologia.salud.gob.mx/anuario/html/anuarios.html

Los datos de la Encuesta Nacional de Salud (2000) y de la Encuesta Nacional de Salud y Nutrición en sus rondas 2006, 2012 y 2018, muestran que, en el año 2000, 6.5 por ciento de la población de 20 años o más fue diagnosticada como diabética, porcentaje que ha venido ascendiendo a 7.5 en 2006, 9.2 en 2012 y 10.3 en 2018. 
Tabla 4: Continuación

\begin{tabular}{|c|c|c|c|c|c|c|}
\hline \multirow{2}{*}{ No. } & \multirow{2}{*}{ Padecimiento } & \multicolumn{5}{|c|}{ Grupos de edad } \\
\hline & & $25-44$ & $45-49$ & $50-59$ & $60-64$ & $650+$ \\
\hline 1 & Infecciones respiratorias agudas & 14,567 & 18,671 & 19,856 & 25,050 & 21,208 \\
\hline 2 & $\begin{array}{l}\text { Infecciones intestinales por otros } \\
\text { organismos }\end{array}$ & 3,052 & 3,586 & 3,875 & 4,814 & 4,988 \\
\hline 3 & Infección de vías urinarias & 3,651 & 4,484 & 5,018 & 6,249 & 6,299 \\
\hline 4 & Úlceras, gastritis y duodenitis & 1,640 & 2,567 & 2,443 & 3,212 & 2,766 \\
\hline 5 & Otitis media aguda & 390 & 591 & 442 & 544 & 381 \\
\hline 6 & $\begin{array}{l}\text { Gingivitis y enfermedades } \\
\text { periodontales }\end{array}$ & 548 & 879 & 753 & 1,009 & 645 \\
\hline 7 & Hipertensión arterial & 344 & 1,058 & 1,571 & 2,290 & 2,185 \\
\hline 8 & Conjuntivitis & 333 & 500 & 431 & 557 & 495 \\
\hline 9 & Amebiasis intestinal & 265 & 351 & 358 & 453 & 416 \\
\hline 10 & $\begin{array}{l}\text { Diabetes mellitus no } \\
\text { insulinodependiente }\end{array}$ & 267 & 917 & 1,365 & 1,862 & 1,404 \\
\hline 11 & Asma y estado asmático & 160 & 242 & 260 & 339 & 299 \\
\hline 12 & Otras helmintiasis & 178 & 185 & 245 & 296 & 290 \\
\hline 13 & Candidiasis urogenital & 465 & 429 & 211 & 161 & 79 \\
\hline 14 & Intoxicación por picadura de alacrán & 225 & 219 & 220 & 252 & 270 \\
\hline 15 & Varicela & 69 & 16 & 11 & 9 & 10 \\
\hline 16 & Neumonías y bronconeumonías & 51 & 84 & 120 & 230 & 518 \\
\hline 17 & Tricomoniasis urogenital & 205 & 188 & 82 & 47 & 21 \\
\hline 18 & Quemaduras & 126 & 111 & 126 & 120 & 106 \\
\hline 19 & Paratifoidea y otras salmonelosis & 133 & 146 & 128 & 116 & 88 \\
\hline 20 & Desnutrición leve & 8 & 9 & 10 & 15 & 37 \\
\hline
\end{tabular}

Fuente: Secretaría de Salud, Dirección General de Epidemiología, Anuarios de Morbilidad 19842019. Disponible en https://epidemiologia.salud.gob.mx/anuario/html/anuarios.html

Los datos que se presentan en la Tabla 6, deben considerarse sólo una aproximación a la prevalencia de diabetes, ya que hay personas que pueden ser diabéticas pero que no han recibido el diagnóstico correspondiente, de aquí la importancia de realizar encuestas sero-epidemiológicas y conocer los resultados de las pruebas aplicadas. Lamentablemente no conocemos los resultados derivados de la toma de muestras que en las encuestas mencionadas previamente se hizo a las personas entrevistadas y hasta el momento, las investigaciones consultadas presentan estimaciones basadas sólo en el "diagnóstico previo", como es el caso de nuestras estimaciones 
(Véanse, por ejemplo: Hernández-Ávila, Gutiérrez y Reynoso-Noverón, 2013; Rojas Martínez et al., 2018).

Tabla 5: Incidencia de las 20 principales enfermedades en la población por grupos de edad (por 100 mil). México 2019

\begin{tabular}{|c|c|c|c|c|c|c|c|}
\hline \multirow{2}{*}{ No. } & \multirow{2}{*}{ Padecimiento } & \multicolumn{6}{|c|}{ Grupos de edad } \\
\hline & & $<1$ & $1-4$ & $5-9$ & $10-14$ & $15-19$ & $20-24$ \\
\hline 1 & $\begin{array}{l}\text { Infecciones respiratorias } \\
\text { agudas }\end{array}$ & 74,718 & 47,367 & 28,371 & 18,143 & 12,761 & 13,777 \\
\hline 2 & $\begin{array}{l}\text { Infecciones intestinales } \\
\text { por otros organismos }\end{array}$ & 10,510 & 8,806 & 5,106 & 3,749 & 3,300 & 4,169 \\
\hline 3 & Infección de vías urinarias & 743 & 1,383 & 1,620 & 1,359 & 2,816 & 4,166 \\
\hline 4 & $\begin{array}{l}\text { Úlceras, gastritis y } \\
\text { duodenitis }\end{array}$ & 71 & 74 & 266 & 683 & 1,023 & 1,388 \\
\hline 5 & $\begin{array}{l}\text { Gingivitis y enfermedad } \\
\text { periodontal }\end{array}$ & 50 & 139 & 404 & 531 & 856 & 1,203 \\
\hline 6 & Conjuntivitis & 2,730 & 1,334 & 863 & 581 & 498 & 712 \\
\hline 7 & Otitis media aguda & 718 & 1,065 & 1,068 & 766 & 620 & 663 \\
\hline 8 & Obesidad & 147 & 96 & 191 & 303 & 309 & 494 \\
\hline 9 & Vulvovaginitis & 14 & 24 & 40 & 116 & 555 & 1,041 \\
\hline 10 & Hipertensión arterial & N.A. & N.A. & N.A. & N.A. & 12 & 74 \\
\hline 11 & $\begin{array}{l}\text { Diabetes mellitus no } \\
\text { insulinodependiente }\end{array}$ & N.A. & N.A. & N.A. & 3 & 8 & 42 \\
\hline 12 & $\begin{array}{l}\text { Intoxicación por picadura } \\
\text { de alacrán }\end{array}$ & 84 & 220 & 241 & 264 & 294 & 269 \\
\hline 13 & Asma & 294 & 461 & 407 & 256 & 143 & 131 \\
\hline 14 & $\begin{array}{l}\text { Insuficiencia venosa } \\
\text { periférica }\end{array}$ & 1 & 1 & 1 & 3 & 10 & 38 \\
\hline 15 & $\begin{array}{l}\text { Faringitis y amigdalitis } \\
\text { estreptocócicas }\end{array}$ & 446 & 380 & 272 & 198 & 165 & 168 \\
\hline 16 & Amebiasis intestinal & 270 & 382 & 268 & 177 & 123 & 124 \\
\hline 17 & Candidiasis urogenital & N.A. & N.A. & N.A. & 18 & 127 & 267 \\
\hline 18 & Dengue no grave & 49 & 43 & 106 & 173 & 161 & 142 \\
\hline 19 & $\begin{array}{l}\text { Neumonías y bronconeu- } \\
\text { monías }\end{array}$ & 822 & 273 & 67 & 31 & 23 & 30 \\
\hline 20 & Accidentes de transporte & 24 & 30 & 36 & 55 & 146 & 192 \\
\hline
\end{tabular}

Fuente: Secretaría de Salud, Dirección General de Epidemiología, Anuarios de Morbilidad 19842019. Disponible en https://epidemiologia.salud.gob.mx/anuario/html/anuarios.html

En el caso de diagnóstico médico de hipertensión basado en estas mismas encuestas, las cifras hacen evidente el incremento en la prevalencia en el grupo de 70 años o más (Tabla 7). 
Tabla 5: Continuación

\begin{tabular}{|c|c|c|c|c|c|c|}
\hline \multirow{2}{*}{ No. } & \multirow{2}{*}{ Padecimiento } & \multicolumn{5}{|c|}{ Grupos de edad } \\
\hline & & $25-44$ & $45-49$ & $50-59$ & $60-64$ & $650+$ \\
\hline 1 & Infecciones respiratorias agudas & 11,305 & 17,745 & 15,563 & 20,689 & 15,660 \\
\hline 2 & $\begin{array}{l}\text { Infecciones intestinales por otros } \\
\text { organismos }\end{array}$ & 3,082 & 4,684 & 3,709 & 4,881 & 3,851 \\
\hline 3 & Infección de vías urinarias & 3,454 & 5,150 & 4,731 & 6,156 & 5,900 \\
\hline 4 & Úlceras, gastritis y duodenitis & 1,128 & 2,091 & 1,623 & 2,198 & 1,639 \\
\hline 5 & Gingivitis y enfermedad periodontal & 924 & 1,375 & 1,231 & 1,650 & 1,150 \\
\hline 6 & Conjuntivitis & 648 & 956 & 869 & 1,081 & 987 \\
\hline 7 & Otitis media aguda & 419 & 751 & 491 & 612 & 359 \\
\hline 8 & Obesidad & 664 & 1,083 & 867 & 883 & 448 \\
\hline 9 & Vulvovaginitis & 769 & 920 & 478 & 438 & 164 \\
\hline 10 & Hipertensión arterial & 301 & 1,002 & 1,078 & 1,617 & 1,448 \\
\hline 11 & $\begin{array}{l}\text { Diabetes mellitus no } \\
\text { insulinodependiente }\end{array}$ & 237 & 878 & 981 & 1,360 & 975 \\
\hline 12 & Intoxicación por picadura de alacrán & 225 & 238 & 206 & 228 & 215 \\
\hline 13 & Asma & 111 & 208 & 169 & 233 & 159 \\
\hline 14 & Insuficiencia venosa periférica & 139 & 410 & 485 & 695 & 628 \\
\hline 15 & $\begin{array}{l}\text { Faringitis y amigdalitis estrepto- } \\
\text { cócicas }\end{array}$ & 101 & 188 & 126 & 181 & 100 \\
\hline 16 & Amebiasis intestinal & 87 & 143 & 112 & 148 & 120 \\
\hline 17 & Candidiasis urogenital & 197 & 262 & 127 & 146 & 57 \\
\hline 18 & Dengue no grave & 124 & 100 & 86 & 70 & 57 \\
\hline 19 & Neumonías y bronconeumonías & 42 & 80 & 102 & 185 & 377 \\
\hline 20 & Accidentes de transporte & 144 & 142 & 95 & 86 & 53 \\
\hline
\end{tabular}

Fuente: Secretaría de Salud, Dirección General de Epidemiología, Anuarios de Morbilidad 19842019. Disponible en https://epidemiologia.salud.gob.mx/anuario/html/anuarios.html

Si tomamos en cuenta esta información en la situación crítica que vive México y el mundo por los efectos de la pandemia, su relevancia es obvia, porque los padecimientos a los que se ha hecho referencia, forman parte de las comorbilidades claramente asociadas a la mortalidad por SARSCoV-2, como puede verse en la Tabla 8. En éste Cuadro se observa la relación claramente diferencial por edad con respecto a las comorbilidades, de tal manera que la obesidad, es un padecimiento previo presente en al menos una de cada tres personas fallecidas entre 30 y 49 años y, en el caso de la hipertensión y la diabetes se hace presente de manera creciente, hasta 
llegar a manifestarse como una comorbilidad en uno de cada dos fallecimientos a partir de los 65 años de edad.

Tabla 6: Porcentaje de la población por grupo de edad que reportó haber recibido un diagnóstico de diabetes, según las Encuestas Nacionales de Salud y Nutrición 2012 y 2018. México

\begin{tabular}{lrr}
\hline \multirow{2}{*}{ Grupos de edad } & 2012 & Año \\
& 0.8 & 2018 \\
\hline 0 a 9 & 2.9 & 0.6 \\
10 a 19 & 8.9 & 3.2 \\
20 a 39 & 19.2 & 8.7 \\
40 a 54 & 25.3 & 18.0 \\
55 a 69 & 23.2 & 25.8 \\
70 o más & 24.9 \\
Fuente: elaboración propia a partir de las bases de datos de ENSANUT 2012 y ENSANUT 2018.
\end{tabular}

Tabla 7: Porcentaje de la población por grupos de edad, que reportó haber recibido un diagnóstico de hipertensión, según las Encuestas Nacionales de Salud y Nutrición 2012 y 2018. México

\begin{tabular}{lrr}
\hline \multirow{2}{*}{ Grupos de edad } & 2012 & Año \\
& 4.018 \\
\hline 0 a 9 & 7.2 & 4.9 \\
10 a 19 & 16.7 & 8.0 \\
20 a 39 & 26.1 & 15.1 \\
40 a 54 & 40.2 & 26.7 \\
55 a 69 & 38.1 & 38.8 \\
70 o más & 46.8 \\
Fuente: elaboración propia a partir de las bases de datos de ENSANUT 2012 y ENSANUT 2018.
\end{tabular}

Reiteramos, los datos producidos por el sistema estadístico nacional en las diferentes áreas de la vida social eran ya clara manifestación del riesgo que enfrentaría la población de presentarse una pandemia como la que se ha presentado el año 2020 y no parece que los encargados de elaborar propuestas estratégicas y respuestas coyunturales para enfrentar los riesgos asociados al crecimiento, envejecimiento, distribución y movilidad de la población, hubieran advertido. 
Tabla 8: Porcentaje de fallecidos por SARS-CoV-2 asociados con Hipertensión, Diabetes y Obesidad por grupo de edad, al 31 de diciembre de 2020. México

\begin{tabular}{lrrr}
\hline Grupo de edad & Hipertensión & Diabetes & Obesidad \\
\hline 0 a 4 & 7.2 & 7.2 & 2.6 \\
5 a 9 & 2.2 & 0.0 & 6.7 \\
10 a 14 & 4.8 & 12.9 & 14.5 \\
15 a 19 & 7.5 & 10.3 & 16.4 \\
20 a 24 & 20.8 & 12.0 & 20.8 \\
25 a 29 & 22.6 & 14.2 & 27.1 \\
30 a 34 & 19.8 & 15.1 & 33.1 \\
35 a 39 & 23.0 & 22.5 & 34.6 \\
40 a 44 & 27.6 & 28.4 & 32.7 \\
45 a 49 & 33.2 & 34.0 & 30.9 \\
50 a 54 & 38.0 & 38.2 & 28.9 \\
55 a 59 & 42.4 & 41.1 & 26.8 \\
60 a 64 & 46.6 & 44.0 & 24.8 \\
65 a 69 & 51.3 & 45.1 & 22.7 \\
70 a 74 & 54.3 & 42.8 & 19.6 \\
75 a 79 & 56.2 & 39.7 & 17.2 \\
80 a 84 & 56.8 & 35.7 & 14.2 \\
85 o más & 54.5 & 27.8 & 9.9 \\
Total & 45.8 & 38.5 & 23.3 \\
\hline
\end{tabular}

Fuente: elaboración propia a partir de la base de datos abiertos de Covid-19. Dirección General de Epidemiología. Secretaría de Salud. Disponible en: https://www.gob.mx/salud/documentos/datos-abiertos-152127

\section{Características de los hogares. Número de residentes. Dependencia económica. Discapacidad}

Las medidas de confinamiento tienen como fin último mantener a las personas en las unidades que habitan y el éxito de esta medida para evitar que el virus se propague, es función de que cada una de ellas pueda mantener esta condición, lo que, a su vez, será una función del rol que juega en el arreglo residencial del cual forma parte, de los recursos económicos con que cuente y el tipo de actividad que desempeñe para sobrevivir en forma adecuada en estas condiciones. Aunque parece una obviedad reiterar que la 
transmisión de una enfermedad infecciosa como la presente está asociada a factores biológicos y sociales, el costo de mantenerse en casa y, además, "guardar la sana distancia" representa un costo social y económico que no todos los individuos pueden solventar.

La información sociodemográfica ofrece un panorama que debe ser tomado en cuenta en la implementación de las medidas de confinamiento y en el caso de México, una serie de encuestas sirve para este fin. Concretamente, la Encuesta Nacional de la Dinámica Demográfica (ENADID) que se ha realizado desde 1992, representa un insumo fundamental en la materia, con la ventaja que su levantamiento más reciente se realizó en el año 2018.

La ENADID-2018 se aplicó en viviendas residenciales y en 98 por ciento de estas unidades las personas formaban un solo hogar; es decir, compartían un mismo gasto y, sólo en el dos por ciento, se identificó más de un hogar. Como el propósito de este análisis, es mostrar algunas condiciones de vulnerabilidad de las personas que residen en la vivienda, se optó en primera instancia por tomar la vivienda como unidad de análisis ya que, en situaciones de confinamiento lo más probable es que los integrantes de más de un hogar en la misma vivienda se apoyen entre sí.

Es evidente que en una crisis sanitaria, las características físicas de las viviendas y la disponibilidad de bienes y servicios, especialmente aquellos indispensables para mantener condiciones de higiene, como el acceso al agua potable, el drenaje o la disposición de los residuos (basura), son de vital importancia, por lo que habrá que mencionar que, con los datos de esta Encuesta se estima que en México, sólo tres de cada cuatro viviendas tiene agua en la misma vivienda, una proporción similar tiene drenaje conectado a una red pública y en el siete por ciento de las viviendas se tiene que compartir el servicio sanitario con los residentes en otras viviendas. Además, como es posible suponer, estas situaciones son claramente diferenciales entre grupos sociales y para el caso que nos ocupa, tienen implicaciones sobre las condiciones de higiene que es necesario mantener para reducir el contagio del virus.

La Tabla 9 muestra el porcentaje de viviendas en las cuales se comparte el servicio sanitario, según el número de residentes y está situación es significativa tanto en localidades urbanas como rurales, por lo que aunque la gente permanezca en sus casas, el peligro de contagio es evidente al compartir este tipo de servicio en el que es difícil suponer que existan condiciones de higiene suficientes para evitarlo; incluso, en ambos tipos de localidades los mayores porcentajes de viviendas en las que se comparte el 
servicio sanitario se observan en viviendas con nueve o más residentes y que representan poco más de diez por ciento del total.

Tabla 9: Porcentaje de viviendas en las que sus residentes comparten el servicio sanitario con los residentes de otra vivienda, según número de residentes y tamaño de la localidad. México, 2018

\begin{tabular}{|c|c|c|}
\hline \multirow{2}{*}{ Número de residentes } & \multicolumn{2}{|c|}{ Tamaño de la localidad } \\
\hline & 15,000 o más & Menos de 15,000 \\
\hline 1 & 7.5 & 9.2 \\
\hline 2 & 6.6 & 10.1 \\
\hline 3 & 6.7 & 10.3 \\
\hline 4 & 5.7 & 9.9 \\
\hline 5 & 6.9 & 9.4 \\
\hline 6 & 6.4 & 10.0 \\
\hline 7 & 5.5 & 9.1 \\
\hline 8 & 7.0 & 6.6 \\
\hline 9 o más & 10.6 & 10.2 \\
\hline Total & 6.6 & 9.7 \\
\hline
\end{tabular}

Fuente: elaboración propia a partir de las bases de datos de ENADID 2018.

Además de las condiciones físicas de las viviendas que para un sector importante de la población le impiden tener condiciones sanitarias óptimas, existen características sociodemográficas de las personas que inciden sobre su vulnerabilidad. Entre éstas tenemos el tipo de arreglo familiar del que forma parte, su edad, actividad, fuente de ingresos y la existencia de alguna incapacidad y que, además de hacer a una persona más o menos vulnerable, definen su grado de dependencia de otros individuos u organizaciones sociales.

Una vez más, los datos de la ENADID-2018, constituyen una fuente de información que permite tener un conocimiento profundo y oportuno, de las condiciones de la población que deben ser tomadas en cuenta, cuando se implementan acciones para enfrentar una pandemia que, como ya se ha mencionado obligan el confinamiento para evitar la propagación del virus. En este apartado, nos concentramos en el análisis de dos grupos de la población: las personas de edad avanzada y las mujeres jefas de familia, que representan dos grupos especialmente vulnerables. 
La distribución del total de viviendas en el país según el número de personas que residen en ellas se muestra en la Tabla 10. Este primer dato es relevante para visualizar las condiciones de confinamiento. En el caso de las viviendas unipersonales, deben tomarse en cuenta las características de la persona para enfrentar con suficientes recursos, esta situación y garantizar su sobrevivencia en la vida cotidiana a través de la procuración de los satisfactores de sus necesidades.

Tabla 10: Distribución del total de viviendas según el número de personas que residen en ellas. México, 2018

\begin{tabular}{lrr}
\hline Número de personas & Número de viviendas & Porcentaje \\
\hline 1 & $3^{\prime}, 881,236$ & 11.2 \\
2 & $6^{\prime} 595,479$ & 19.1 \\
3 & $6^{\prime}, 930,638$ & 20.1 \\
4 & $7^{\prime} 634,497$ & 22.1 \\
5 & $4^{\prime} 942,464$ & 14.3 \\
6 & $2^{\prime} 281,627$ & 6.7 \\
7 & $1^{\prime} 102,993$ & 3.2 \\
8 & 566,862 & 1.6 \\
9 o más & 581,104 & 1.7 \\
Total & $34^{\prime} 516,900$ & 100.0 \\
\hline
\end{tabular}

Fuente: elaboración propia a partir de las bases de datos de la ENADID 2018.

En 11.2 por ciento de las viviendas vive una persona sola, esta condición por sí misma no implica que sea vulnerable; sin embargo, algunas de sus características pueden hacerla más o menos vulnerable en el confinamiento. Por lo que analizaremos algunas de las características de las personas que viven solas.

Según su distribución por sexo y edad, observamos en la Tabla 11 que, en los grupos más jóvenes, los hombres representan claramente los mayores porcentajes, situación que cambia a partir de los 55 años, la que está asociada al mayor nivel de sobrevivencia de las mujeres y que se constata con los datos de la Tabla 12 en el cual, al incorporar en el análisis el estado conyugal, conforme se avanza en la edad los porcentajes de mujeres viudas son claramente superiores a los de los hombres.

Dado nuestro interés por identificar condiciones de vulnerabilidad en grupos específicos de la población, concentraremos nuestra atención en la población de 70 años o más. 
Tabla 11: Distribución porcentual por sexo y grupo de edad de la población residente en viviendas unipersonales. México, 2018

\begin{tabular}{lrrrr}
\hline Grupo de edad & \multicolumn{2}{c}{ Sexo } & Total & \% Total \\
& Hombre & Mujer & & \\
\hline 15 a 19 & 64.5 & 35.5 & 100.0 & 0.8 \\
20 a 24 & 70.0 & 30.0 & 100.0 & 3.5 \\
25 a 29 & 75.8 & 24.2 & 100.0 & 4.7 \\
30 a 34 & 75.1 & 24.9 & 100.0 & 6.3 \\
35 a 39 & 76.0 & 24.0 & 100.0 & 6.9 \\
40 a 44 & 77.6 & 22.4 & 100.0 & 7.1 \\
45 a 49 & 65.6 & 34.4 & 100.0 & 7.9 \\
50 a 54 & 59.0 & 41.1 & 100.0 & 9.4 \\
55 a 59 & 48.2 & 51.8 & 100.0 & 9.8 \\
60 a 64 & 43.4 & 56.6 & 100.0 & 9.7 \\
65 a 69 & 41.1 & 58.9 & 100.0 & 9.0 \\
70 a 74 & 36.7 & 63.3 & 100.0 & 9.2 \\
75 a 79 & 40.5 & 59.5 & 100.0 & 6.7 \\
80 a 84 & 39.4 & 60.6 & 100.0 & 5.1 \\
85 y más & 40.4 & 59.6 & 100.0 & 3.9 \\
Total & 55.1 & 44.9 & 100.0 & 100.0 \\
\hline
\end{tabular}

Fuente: elaboración propia a partir de las bases de datos de la ENADID 2018.

Las personas de 70 o más años representan casi seis por ciento de la población total del país, pero en 16 por ciento de las viviendas del país reside al menos una persona en este grupo de edad.

Las viviendas en donde sólo viven personas de 70 o más años, son poco más de 1.5 millones y en éstas viven una, dos, tres y hasta cuatro personas, para dar un total de 2.1 millones de personas de edad avanzada y, en poco menos de un millón de las viviendas viven solos. Al respecto, debe llamar la atención que dos de cada tres viviendas unipersonales en las que residen personas de edad avanzada, están habitadas por mujeres, según se ve en la Tabla 13. 
Tabla 12: Estado Conyugal de la persona que vive en una vivienda unipersonal por grupo de edad y sexo. México, 2018

\begin{tabular}{|c|c|c|c|c|c|c|}
\hline \multirow[b]{2}{*}{ Grupo de edad } & \multicolumn{6}{|c|}{ Estado Conyugal } \\
\hline & Sexo & $\begin{array}{l}\text { En unión } \\
\text { conyugal }\end{array}$ & $\begin{array}{l}\text { Separada o } \\
\text { divorciada }\end{array}$ & Viuda & Soltera & Total \\
\hline \multirow{2}{*}{15 a 19} & $\mathrm{H}$ & 0.6 & 2.3 & 0.0 & 97.1 & 100.0 \\
\hline & M & 11.1 & 6.4 & 3.5 & 79.0 & 100.0 \\
\hline \multirow{2}{*}{20 a 24} & $\mathrm{H}$ & 5.6 & 16.8 & 0.0 & 77.6 & 100.0 \\
\hline & M & 4.9 & 4.2 & 0.6 & 90.3 & 100.0 \\
\hline \multirow{2}{*}{25 a 29} & $\mathrm{H}$ & 7.3 & 20.1 & 0.0 & 72.6 & 100.0 \\
\hline & M & 6.9 & 11.5 & 0.0 & 81.6 & 100.0 \\
\hline \multirow{2}{*}{30 a 34} & $\mathrm{H}$ & 9.6 & 27.2 & 0.0 & 63.2 & 100.0 \\
\hline & M & 5.9 & 23.5 & 1.1 & 69.5 & 100.0 \\
\hline \multirow{2}{*}{35 a 39} & $\mathrm{H}$ & 9.5 & 27.2 & 0.0 & 63.3 & 100.0 \\
\hline & M & 5.8 & 19.5 & 1.9 & 72.8 & 100.0 \\
\hline \multirow{2}{*}{40 a 44} & $\mathrm{H}$ & 11.0 & 48.7 & 1.6 & 38.7 & 100.0 \\
\hline & M & 9.8 & 39.7 & 9.8 & 40.7 & 100.0 \\
\hline \multirow{2}{*}{45 a 49} & $\mathrm{H}$ & 10.9 & 48.0 & 1.9 & 39.2 & 100.0 \\
\hline & M & 9.8 & 39.7 & 9.8 & 40.7 & 100.0 \\
\hline \multirow{2}{*}{50 a 54} & $\mathrm{H}$ & 11.4 & 47.0 & 7.9 & 33.7 & 100.0 \\
\hline & M & 7.5 & 45.9 & 16.6 & 30.0 & 100.0 \\
\hline \multirow{2}{*}{55 a 59} & $\mathrm{H}$ & 12.0 & 51.8 & 8.6 & 27.6 & 100.0 \\
\hline & M & 5.8 & 36.4 & 31.1 & 26.7 & 100.0 \\
\hline \multirow{2}{*}{60 a 64} & $\mathrm{H}$ & 11.7 & 46.0 & 18.6 & 23.7 & 100.0 \\
\hline & M & 3.5 & 32.9 & 45.7 & 17.9 & 100.0 \\
\hline \multirow{2}{*}{65 a 69} & $\mathrm{H}$ & 8.8 & 40.5 & 32.1 & 18.6 & 100.0 \\
\hline & M & 2.5 & 24.7 & 56.6 & 16.2 & 100.0 \\
\hline \multirow{2}{*}{70 o más } & $\mathrm{H}$ & 7.5 & 21.2 & 57.8 & 13.5 & 100.0 \\
\hline & M & 0.9 & 12.2 & 75.0 & 11.9 & 100.0 \\
\hline
\end{tabular}

Fuente: elaboración propia a partir de las bases de datos de la ENADID 2018.

Establecer la forma en que puede vivir el confinamiento esta población, requiere de respuestas estratégicas y coyunturales, porque la población de edad avanzada crecerá en términos absolutos y relativos en los próximos años y en la situación actual, no puede desconocerse la situación que los datos describen. 
Tabla 13: Viviendas en las que sólo residen personas de 70 o más años y su distribución porcentual según sexo y número de personas. México, 2018

\begin{tabular}{lr}
\hline Número de personas & Distribución \\
\hline Viviendas unipersonales & \\
Un hombre solo & 38.9 \\
& 374,581 \\
Una mujer sola & 61.1 \\
& 589,189 \\
Total & 100.0
\end{tabular}

Viviendas de dos personas

Un hombre y una mujer

94.5

510,009

Dos hombres

Dos mujeres

Total

Viviendas de tres personas

Un hombre y dos mujeres

Dos hombres y una mujer

Tres hombres

Tres mujeres

Total

Viviendas de cuatro personas

Cuatro mujeres

Total

Total de viviendas en dónde sólo viven personas de 70 o más años 
Por otra parte, de los ingresos que reciben de programas gubernamentales dependen casi un millón de personas que viven en estas viviendas y poco más de cien mil no tienen una fuente de ingresos regular y, por lo tanto, viven de lo que pueden obtener, desempeñando a veces alguna actividad por la que reciben un pago en dinero o en especie, u obtienen algún producto de la caridad pública.

Otra condición relevante entre esta población la constituye la existencia de limitaciones físicas y que dificulta su existencia cotidiana.

La ENADID-2018, indagó ocho posibles condiciones asociadas con la discapacidad o las limitaciones que tendría una persona para realizar una actividad y que captan: i) si no puede hacerlo, ii) si lo hace con mucha dificultad, iii) si lo hace con alguna dificultad, o iv) si no tiene dificultad para caminar, ver, mover o usar brazos o manos, aprender, recordar o concentrarse, oír, bañarse o vestirse o comer, hablar o realizar sus actividades diarias por problemas emocionales o mentales. A partir de la respuesta a las preguntas que indagaron su capacidad en cada una de ellas, la población fue clasificada en tres categorías; a) con discapacidad, b) con limitación $o, c)$ sin discapacidad o limitación. La primera categoría, "Incluye a las personas que tienen como respuesta "No puede hacerlo" o, "Lo hace con mucha dificultad" en al menos una de las actividades por la cuales se indagó. La segunda categoría, "Incluye a las personas que únicamente tienen como respuesta "Lo hace con poca dificultad" en al menos una de las actividades y la tercera categoría, "incluye a las personas que tienen como respuesta "No tiene dificultad" en todas las actividades". ${ }^{20}$ Aunque creemos que, para la población en general, esta clasificación sobreestima el número de personas con discapacidad, para los propósitos de este texto, decidimos mantener la clasificación porque cualquier limitación física o mental puede generar graves consecuencias para las personas de edad avanzada por el confinamiento y la falta de interacción con otras personas en esta pandemia.

Los niveles de discapacidad o limitación observados en la Tabla 14, que muestran las personas en las viviendas en las que sólo residen personas de edad avanzada según su número, en conjunto significan que una de cada cuatro personas está discapacitada. Con excepción de las viviendas unipersonales, puede suponerse que estas personas enfrentan esta condición ayudándose entre sí, pero el panorama es aún más dramático si sumamos las personas sólo con limitaciones, porque más de 50 por ciento está en condiciones de discapacidad o limitación.

20 INEGI. Encuesta Nacional de la Dinámica Demográfica 2018. Tabulados oportunos. 
Tabla 14: Distribución porcentual por condición de discapacidad o limitación de las personas en viviendas en las que sólo viven personas de 70 o más años, según su número. México, 2018

\begin{tabular}{lrrrrrr}
\hline $\begin{array}{l}\text { Condición } \\
\text { de }\end{array}$ & $\begin{array}{c}\text { Vivienda con dos } \\
\text { discapacidad }\end{array}$ & $\begin{array}{r}\text { personas } \\
\text { unipersonal }\end{array}$ & $\begin{array}{c}\text { Persona } \\
1\end{array}$ & $\begin{array}{c}\text { Persona } \\
\text { Pivienda con tres personas }\end{array}$ & $\begin{array}{c}\text { Persona } \\
\text { Persona }\end{array}$ & $\begin{array}{c}\text { Persona } \\
2\end{array}$ \\
\hline $\begin{array}{l}\text { Con } \\
\text { discapacidad }\end{array}$ & 33.8 & 34.3 & 33.8 & 16.0 & 17.0 & 43.6 \\
$\begin{array}{l}\text { Con } \\
\text { limitación }\end{array}$ & 43.7 & 43.1 & 39.8 & 48.4 & 49.7 & 32.2 \\
$\begin{array}{l}\text { Sin } \\
\text { discapacidad } \\
\text { o limitación }\end{array}$ & 22.5 & 22.6 & 26.4 & 35.6 & 33.3 & 24.2 \\
Total & 100.0 & 100.0 & 100.0 & 100.0 & 100.0 & 100.0 \\
\hline
\end{tabular}

Fuente: elaboración propia a partir de las bases de datos de la ENADID 2018.

Completamos el análisis de las condiciones de este grupo de población, al estimar con los datos de esta misma encuesta, que 89 por ciento de las personas de 70 o más años está afiliado a alguna organización que ofrece servicios de cuidado de la salud y por lo tanto, al menos formalmente tiene acceso a estos servicios; sin embargo, es importante destacar que después del Instituto Mexicano del Seguro Social, al que declaró estar afiliado 42 por ciento de esta población, 34 por ciento estaba afiliado al Seguro Popular, por lo que su desaparición y substitución por el Instituto de Salud para el Bienestar (INSABI) a partir del 1 de enero de 2020, unos días antes del inicio de la pandemia, pudo haber tenido importante consecuencias para esta población. El INSABI ofrece atención de primer y segundo nivel, por lo que ante padecimientos que impliquen un mayor nivel de atención y especialización, el usuario debe pagar una cuota. Sin embargo, lo que es más grave, es que, hasta el mes de octubre de 2020, el INSABI carecía de Reglas de Operación.

En el INSABI, se tiene la intención de ofrecer todos los servicios exentando su cobro, pero se mantiene el estudio socioeconómico para ubicar en cierto nivel al paciente. No es clara la intención de seguir con esta clasificación y no establecer que sólo al hecho de que una persona carezca de servicio médico que ofrezca la seguridad social, le da derecho a estar exento del pago. No se puede hablar de acceso universal gratuito a las personas 
que carezcan de seguridad social, mientras no sea esta carencia el único criterio para la gratuidad de los servicios médicos. No tiene ningún sentido exentar a todos los niveles socioeconómicos como lo plantea el Acuerdo del Secretario de Salud publicado el 30 de noviembre de 2020 en el Diario Oficial de la Federación, a menos que se quieran justificar los casos en que se cobre el servicio o se niegue la atención médica a los pacientes que lo requieran, como lo establecía la ley vigente hasta antes de esta fecha.

La información sociodemográfica disponible, hacía evidente el acceso limitado a servicios médicos para la mayor parte de la población y esta situación, debió considerarse y debe seguir siendo considerada ante los riesgos que representan brotes epidémicos como la Covid-19, porque los servicios médicos en los hospitales públicos han negado sistemáticamente la atención a enfermos por el SARS-CoV-2.

Otro grupo de interés lo constituyen las mujeres jefas de hogar, porque múltiples condiciones las ponen en situación de riesgo y por tanto, sus condiciones de vulnerabilidad se pueden incrementar en una coyuntura como la que representa esta pandemia. Para describir sus condiciones, se han analizado los hogares familiares con jefatura femenina a partir de los datos de la ENADID-2018.

Cuando la unidad de análisis lo constituye el hogar, la información muestra que 28 por ciento de los hogares está encabezado por mujeres. El 60 por ciento de las mujeres jefas de hogar declaró desempeñar una actividad económica fuera del ámbito doméstico la semana anterior a la encuesta. Aunque 40 por ciento no desempeño una actividad económica para el mercado, la identificación de una mujer como la jefa de hogar, refleja la autoridad que ejerce sobre sus integrantes y la responsabilidad para mantener el funcionamiento de esta organización con la realización de trabajo doméstico indispensable para la supervivencia y reproducción de la familia.

Siete de cada diez mujeres que no desempeñaron una actividad económica fuera del hogar declararon dedicarse a labores domésticas. Esto simplemente muestra la dependencia económica de este sector de la población al no tener una fuente de ingresos producto de su trabajo fuera del hogar; sin embargo, la mujer es el personaje alrededor del cual se organiza la vida cotidiana de los miembros de los hogares familiares. No puede desconocerse el muy importante papel que juegan las mujeres en el funcionamiento del hogar y que los datos hacen evidente.

Se estima que existían 7.5 millones de hogares de este tipo y se describen a continuación algunas de las características sociodemográficas más relevantes, tanto de los hogares como de las jefas de hogar. 
El INEGI, ha usado en las Encuesta Nacionales realizadas en viviendas una estratificación socioeconómica que las ubica en cuatro estratos: Bajo, Medio Bajo, Medio Alto y Alto. La estratificación se forma a partir de 34 indicadores que reflejan las condiciones de la población y de las viviendas que habitan, captados en el Censo de Población y vivienda 2010 (INEGI. 2019).

Según la información que se presenta en la Tabla 15, no hay grandes diferencias en la distribución de hogares según estrato socioeconómico de acuerdo con su jefatura, aunque destaca el hecho de que en el estrato bajo, los hogares con jefatura femenina presentan el menor porcentaje, 15 por ciento; así como el mayor porcentaje en el estrato medio alto. Un elemento que explica las diferencias en la distribución según estrato socioeconómico es la conformación de los hogares según el número de personas que lo integran y sus características socioeconómicas. Los hogares con jefatura femenina tienen en promedio 3.6 personas contra 3.9 del total de hogares familiares y un análisis del estrato en el que se ubica el hogar según el número de sus integrantes, muestra que los hogares con menor número de integrantes presentan los mayores porcentajes en el estrato alto, simplemente porque en éstos, hay más personas que contribuyen a satisfacer las necesidades económicas del hogar y aportan sus ingresos con este objetivo.

Tabla 15: Distribución porcentual del total de hogares, de los hogares familiares y de hogares familiares con jefatura femenina según estrato socioeconómico. México, 2018

\begin{tabular}{lrrr}
\hline Estrato & Total de hogares & \multicolumn{2}{c}{ Hogares familiares } \\
& & Total & Con jefatura femenina \\
\hline Bajo & 18.1 & 18.7 & 15.0 \\
Medio bajo & 49.7 & 50.3 & 51.5 \\
Medio alto & 21.9 & 21.1 & 24.0 \\
Alto & 10.3 & 9.9 & 9.5 \\
Total & 100.0 & 100.0 & 100.0 \\
Total (millones) & 35.3 & 31.0 & 7.5 \\
\hline
\end{tabular}

Fuente: elaboración propia a partir de las bases de datos de la ENADID 2018.

La idea de que la familia pequeña vive mejor, es válida siempre y cuando aquellos de sus integrantes que están en capacidad de desempeñar una actividad económica puedan hacerlo y tengan un empleo bien remunerado. Sin embargo, ante las elevadas tasas de desempleo e informalidad, la rea- 
lidad obliga al Estado a proveer recursos a los hogares que no pueden satisfacer adecuadamente sus necesidades y para esto, implementa diversos programas gubernamentales cuyo objetivo es precisamente hacer transferencias monetarias a las personas que lo necesitan.

En el caso de los hogares familiares cuya jefa es una mujer, los datos de la ENADID-2018, permiten estimar el porcentaje de hogares cuya jefa recibe recursos de programas gubernamentales. Los resultados se presentan en la Tabla 16 y hacen evidente la importancia de contar con recursos de los programas sociales en una coyuntura como la que genera la pandemia $\mathrm{y}$, aunque no es posible establecer con la información de la Encuesta lo que estas transferencias representan como proporción del ingreso total del hogar, puede observarse que en poco más de 40 por ciento de los hogares en el estrato bajo, la jefa del hogar recibe transferencias monetarias de programas de gobierno.

Tabla 16: Porcentaje de hogares familiares con jefatura femenina en los cuales la jefa del hogar recibe ingresos de programas de gobierno, según el número de sus integrantes por estrato socioeconómico. México, 2018

\begin{tabular}{|c|c|c|c|c|c|}
\hline \multirow{2}{*}{$\begin{array}{l}\text { Número de } \\
\text { personas que } \\
\text { integran el hogar }\end{array}$} & \multicolumn{5}{|c|}{ Estrato socioeconómico } \\
\hline & Bajo & Medio bajo & Medio alto & Alto & Total \\
\hline 2 & 42.7 & 19.0 & 10.4 & 5.5 & 18.5 \\
\hline 3 & 40.5 & 16.3 & 7.4 & 3.3 & 15.9 \\
\hline 4 & 44.6 & 18.6 & 10.6 & 3.8 & 19.3 \\
\hline 5 & 46.9 & 22.1 & 12.6 & 2.6 & 23.0 \\
\hline 6 & 47.1 & 24.0 & 13.3 & 4.4 & 24.5 \\
\hline 7 & 43.9 & 28.6 & 16.2 & 10.1 & 28.3 \\
\hline 8 & 52.9 & 20.6 & 20.1 & 32.9 & 27.4 \\
\hline 9 o más & 47.0 & 28.8 & 14.6 & 38.4 & 30.1 \\
\hline Total & 43.7 & 19.4 & 10.3 & 4.3 & 19.5 \\
\hline
\end{tabular}

Fuente: elaboración propia a partir de las bases de datos de la ENADID 2018.

Además, si se toman en cuenta otras fuentes de ingresos, lo que los datos permiten observar es que una de cada tres jefas de hogar que reciben remesas, son también apoyadas por transferencias monetarias de programas de gobierno. Esto es algo especialmente relevante en el período de la pandemia en el cual, ocho de cada diez migrantes han disminuido el monto de las remesas y siete de cada diez personas que han dejado de enviar remesas 
lo han hecho a causa de la pandemia, según información de la Organización Internacional para las Migraciones de la ONU (OIM, 2020), generada a través de un sondeo realizado a partir del mes de junio de 2020 y aún vigente en la fecha de redacción de este texto. Además, la implementación de los programas de transferencias monetarias del gobierno ha sufrido retrasos en su implementación que han afectado a proporciones significativas de la población beneficiaria de éstos y podrían haber generado situaciones críticas para los hogares jefaturados por mujeres.

Sin embargo, debe subrayarse que nuestros cálculos basados en las cifras más recientes del Banco de México, permiten estimar que las denominadas remesas familiares (formalmente registradas) que se recibieron entre enero y diciembre de 2020, alcanzaron 40,607 millones de dólares, lo que además de representar un récord, muestra el esfuerzo extraordinario que han tenido que hacer los mexicanos que trabajan en el extranjero y casi en su totalidad en los Estados Unidos, para proveer de recursos a sus familias en México.

Las referencias anteriores muestran la necesidad de analizar lo que en la pandemia han representado para todos los hogares las transferencias de programas gubernamentales y las remesas, tema que supera los objetivos de este texto, pero por su importancia debe mencionarse.

Con respecto a las características demográficas de las jefas de hogar, una de cada tres mujeres jefas de hogar tiene 60 o más años y con excepción de las mujeres menores que tienen entre 15 y 29 años, son en su mayoría viudas, separadas o divorciadas, Casi 80 por ciento de las mujeres en el grupo de edad más avanzada se encuentran en esta condición (Tabla 17).

Por otra parte, como ya se mencionó, en esta pandemia, resulta fundamental la posibilidad de acceder a los servicios médicos por estar afiliado a alguna organización que ofrece servicios de cuidado de la salud. Aunque la simple afiliación no garantice recibir servicios adecuados ante la limitación real de recursos en el sector público y, como ya se mencionó, el desorden administrativo que produjo la reorganización del sector, precisamente en un periodo inmediatamente previo al inicio de la pandemia. 
Tabla 17: Distribución porcentual de las mujeres jefas de hogares familiares según estado conyugal por edad. México, 2018

\begin{tabular}{lrrcrr}
\hline $\begin{array}{l}\text { Grupo } \\
\text { de edad }\end{array}$ & Soltera & Casada & Unión Libre & $\begin{array}{r}\text { Viuda, separada } \\
\text { o divorciada }\end{array}$ & Total \\
\hline 15 a 29 & 15.5 & 20.6 & 37.7 & 26.2 & $\begin{array}{r}100.0 \\
(7.2)\end{array}$ \\
30 a 59 & 13.3 & 20.4 & 14.3 & 52.0 & $\begin{array}{r}100.0 \\
(62.7)\end{array}$ \\
60 o más & 5.7 & 12.6 & 3.2 & 78.5 & 100.0 \\
& & & & & $(30.1)$ \\
Total & 11.1 & 18.1 & 12.6 & 58.2 & $\begin{array}{r}100.0 \\
(100.0)\end{array}$ \\
\hline
\end{tabular}

Fuente: elaboración propia a partir de las bases de datos de la ENADID 2018.

Según los datos de la Tabla 18, 87 por ciento de las jefas de hogar declara estar afiliada a algún servicio de cuidado de la salud a cargo de una entidad pública o privada y los mayores porcentajes los representan el Instituto Mexicano del Seguro Social y el Seguro Popular con porcentajes muy similares: 38 y 37 por ciento, respectivamente. ${ }^{21}$ Sólo 12 por ciento restante está afiliado a otra organización. Es decir, sin acceso al Seguro Popular sólo 50 por ciento de las jefas de hogar estarían afiliadas a alguna organización que provee este tipo de servicios.

Reiteramos, estar afiliada al IMSS o a otra entidad pública no garantiza el acceso a los servicios, como lo ha hecho evidente esta pandemia, pero es la única posibilidad que tiene la mayoría de la población que, en el caso del Seguro Popular acogía a los trabajadores que viven de realizar una actividad en el sector informal. Al respecto, para las empleadas domésticas la opción es ahora el INSABI, porque los esfuerzos para afiliarlas al Seguro Social no han tenido éxito, ya que las mujeres que las emplean en su mayoría, no tienen recursos suficientes para pagar las cuotas del IMSS. En reporte oficial del propio Instituto al mes de marzo de 2020 y a un año de haber sido puesto en marcha el Programa Piloto para la Incorporación de Personas Trabajadoras del Hogar, sólo 14 mil trabajadoras habían sido afi-

${ }^{21}$ En el cálculo e estos porcentajes se ha eliminado la duplicación y se ha dado prioridad a la afiliación al IMSS. El 39 por ciento se declaró afiliada al Seguro Popular, pero dos por ciento, también estaba afiliada al IMSS. 
liadas. ${ }^{22}$ Se estima según los datos de la Encuesta Nacional de Ocupación que alrededor de 2.2 millones de personas son mujeres empleadas remuneradas que realizan labores domésticas. ${ }^{23} \mathrm{y}$ en esta etapa de confinamiento para enfrentar la pandemia, un tema relevante es el efecto que ésta ha tenido entre este sector de trabajadoras, porque probablemente en una gran proporción habrá perdido el empleo, aunque hasta ahora, no hay suficiente evidencia de la situación y lo que se dice al respecto son percepciones de lo que sucede en algunos otros sectores.

Tabla 18: Porcentajes de mujeres jefas de hogar afiliadas a organizaciones que ofrecen servicios de cuidados a la salud por edad. México, 2018

\begin{tabular}{lr}
\hline Grupo de edad & Porcentaje (\%) \\
\hline 15 a 29 & 83.9 \\
30 a 59 & 85.7 \\
60 o más & 89.5 \\
Total & 86.8 \\
\hline
\end{tabular}

Fuente: elaboración propia a partir de las bases de datos de la ENADID 2018.

Otra característica de las jefas de hogar que contribuye a su vulnerabilidad, son sus condiciones de discapacidad o las limitaciones que tenga para realizar sus actividades cotidianas. Casi la mitad de la población femenina que cumple el papel de jefa del hogar tiene alguna discapacidad o limitación según la clasificación que hizo la ENADID-2018, observable en la Tabla 19. Recordemos que la discapacidad significa que la persona no puede caminar, mover los brazos, ver, oír, recordar o, bañarse, comer o vestirse o, que estas actividades las realiza con gran dificultad, incluso usando aparatos de ayuda, por lo que la situación de quienes se encuentran en este grupo puede ser especialmente grave durante el confinamiento.

En otro orden de ideas, las medidas de confinamiento y cuarentena que recomiendan a las personas que no salgan de sus hogares y que obligaron al cierre de escuelas y guarderías, han hecho que la carga de trabajo doméstico y de cuidado de las personas en el hogar sin remuneración haya crecido, especialmente para las mujeres. Si ya de por sí esta situación era evidente, en el futuro se podrá documentar con nuevos datos referidos al periodo de confinamiento. Por el momento, contamos con información de gran oportunidad proveniente de la Encuesta Nacional Sobre Uso del

22 IMSS. Ciudad de México, martes 31 de marzo de 2020. Boletín de prensa No. 161/2020. En el mes de noviembre se reportó un total de 19 mil empleadas domésticas afiliadas.

23 Datos del cuarto trimestre de 2019. ENOE. INEGI. 
Tiempo 2019 (ENUT-2019.), cuyos resultados se dieron a conocer el mes de junio de 2020 y que constatan el importante papel de la mujer en el hogar en la actual coyuntura y la carga que le representa el cuidado de otros miembros del hogar.

Tabla 19: Distribución porcentual de las mujeres jefas de hogar según condición de discapacidad o limitación por grupos de edad. México, 2018

\begin{tabular}{lrrrr}
\hline \multirow{2}{*}{ Grupo de edad } & \multicolumn{4}{c}{ Condición de incapacidad o limitación } \\
& $\begin{array}{r}\text { Con } \\
\text { discapacidad }\end{array}$ & $\begin{array}{r}\text { Con } \\
\text { limitación }\end{array}$ & $\begin{array}{r}\text { Sin discapacidad } \\
\text { o limitación }\end{array}$ & Total \\
\hline 15 a 29 & 3.3 & 14.3 & 82.4 & 100.0 \\
30 a 59 & 8.0 & 30.1 & 61.9 & 100.0 \\
60 o más & 29.6 & 41.4 & 29.0 & 100.0 \\
Total & 14.1 & 32.4 & 53.5 & 100.0 \\
\hline
\end{tabular}

Fuente: elaboración propia a partir de las bases de datos de la ENADID 2018.

Los datos de la ENUT-2019, se refieren a la población de 12 años o más y se presentan en la Tabla 20. El número de horas promedio por actividad, está calculado con respecto al total de la población que declaró realizarla $\mathrm{y}$ este es un detalle importante porque aunque mujeres y hombres declaren hacer trabajo doméstico para el propio hogar (52.5 y 45.8 millones de personas respectivamente), el número de horas que dedican las mujeres al trabajo no remunerado en el propio hogar, casi triplica al que realizan los hombres (30.8 vs 11.6) y un aspecto relevante es el número de horas que dedican las mujeres al cuidado de los miembros de su hogar. Al cuidado de los niños las mujeres le dedican 24.1 horas en promedio y al cuidado de quienes tienen 60 años o más le dedican 17.3 horas a la semana.

Puede suponerse que el confinamiento demandará mayor número de horas dedicadas especialmente al cuidado de los niños, lo que implicará, además que, al haberse cerrado las escuelas, las mujeres deban actuar como sus profesoras.

Para hacer más demandante la actividad cotidiana de los miembros adultos del hogar que desempeñan tareas de cuidado de los niños, la educación a distancia no es una tarea que se pueda realizar en una proporción importante de los hogares en México. 
Conocimiento sociodemográficico y respuesta institicioional a una pandemia. El caso de México / C. WELTI y A.C. RAMÍrREZ

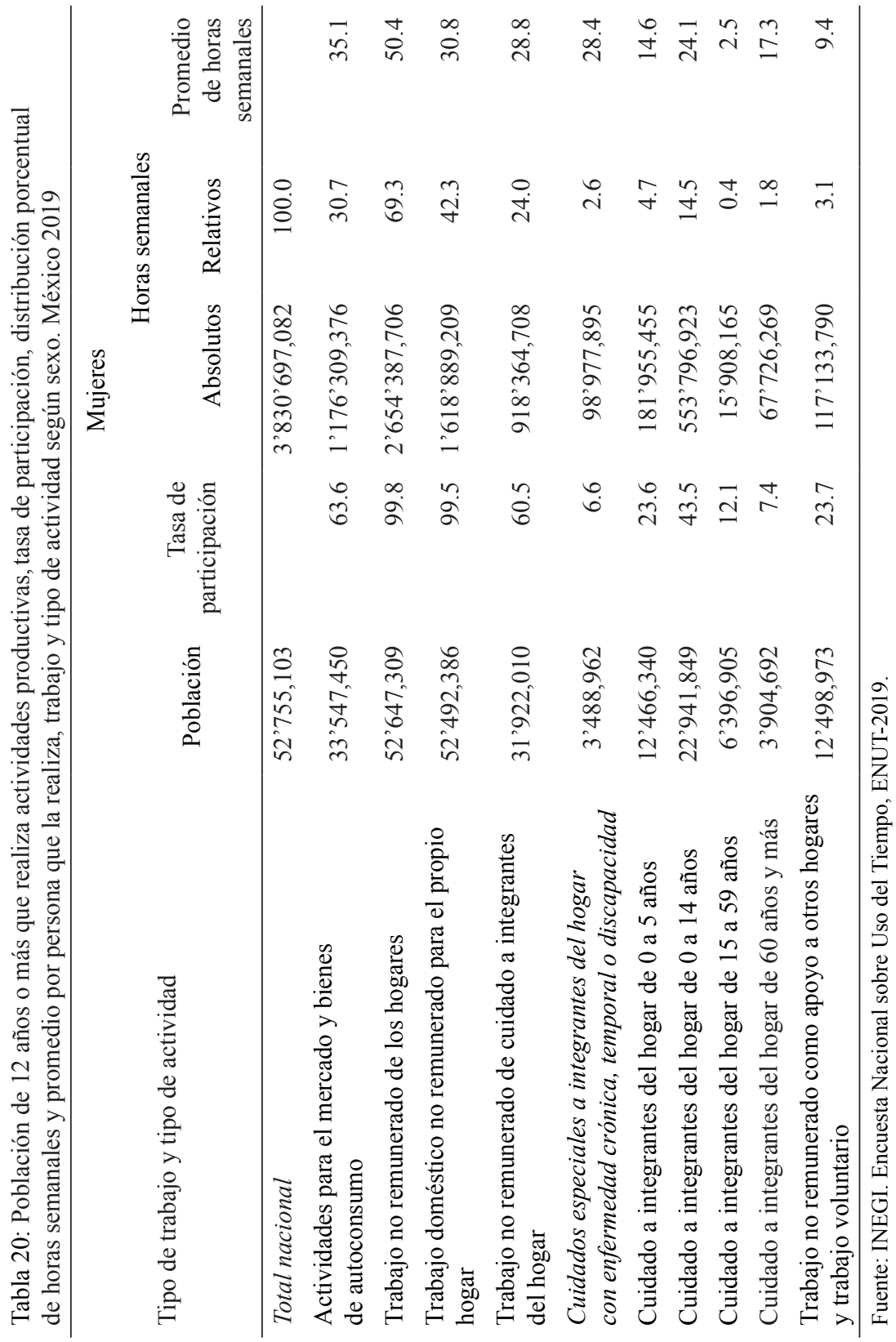




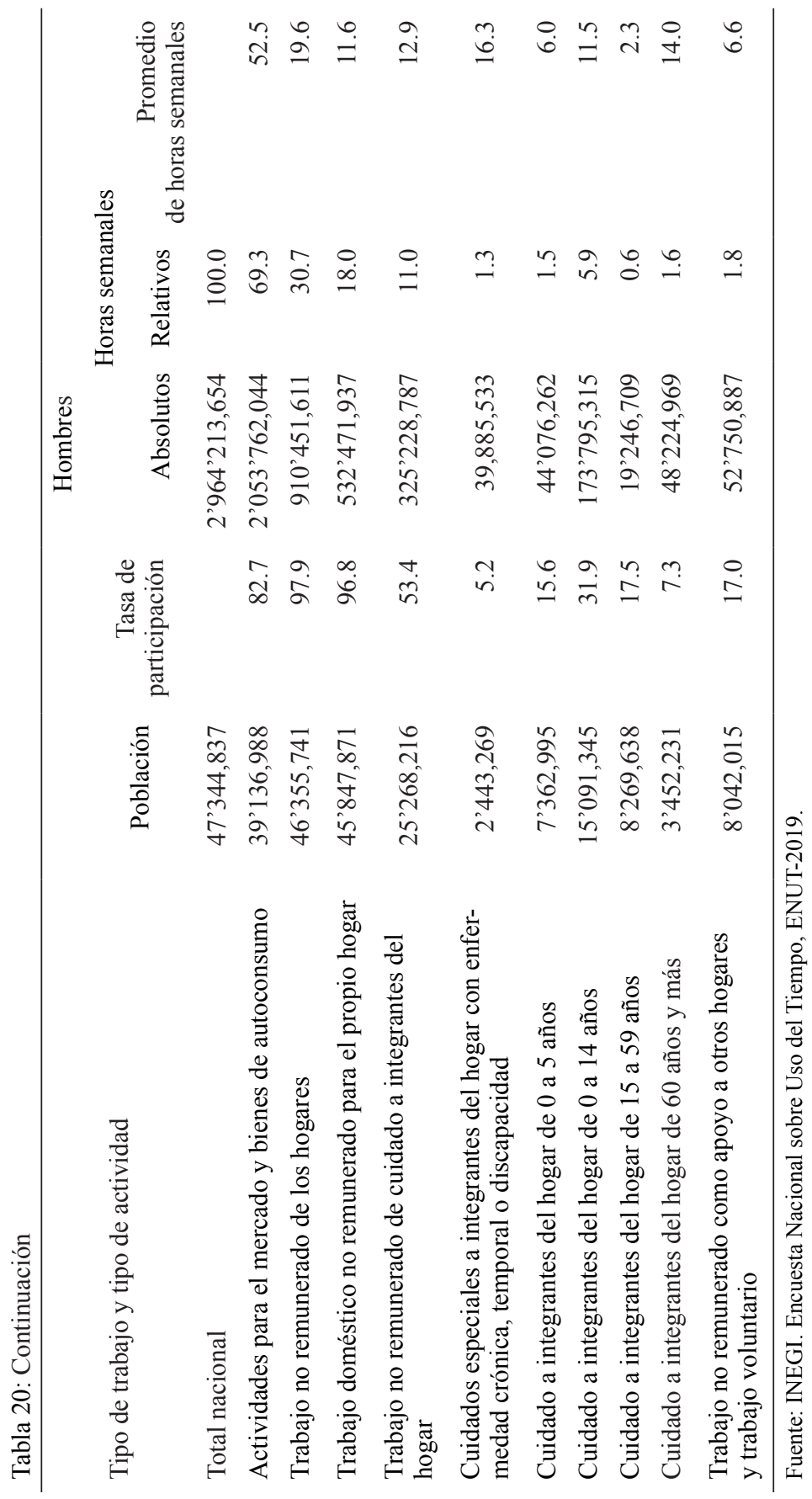


Los datos más recientes provenientes de la Encuesta Nacional sobre Disponibilidad y Uso de TIC en Hogares, ENDUTIH 2019, muestran que los hogares en el "estrato bajo", en 80 por ciento no cuentan con conexión a Internet y uno de cada cinco ni siquiera televisión tiene, por lo que probablemente la educación a distancia está siendo un ejercicio de simulación entre amplios sectores de la población; sin embargo, a la jefa de hogar se le asignan estas nuevas responsabilidades que debe asumir sin tiempo disponible, sin recursos materiales y mucho menos didácticos para cumplir ahora el papel de docente en su propio hogar (Tabla 21).

Tabla 21: Porcentajes de hogares con equipamiento de tecnología de información y comunicaciones por estrato socioeconómico, según tipo de equipo. México, 2019

\begin{tabular}{lrrrrr}
\hline $\begin{array}{l}\text { Estrato } \\
\text { socio } \\
\text { económico }\end{array}$ & Computadora & $\begin{array}{r}\text { Conexión } \\
\text { a Internet }\end{array}$ & $\begin{array}{r}\text { Tele } \\
\text { visión }\end{array}$ & $\begin{array}{r}\text { Televisión } \\
\text { de paga }\end{array}$ & Telefonía \\
\hline Bajo & 16.4 & 19.0 & 83.0 & 33.9 & 79.9 \\
Medio bajo & 40.2 & 55.1 & 93.5 & 43.2 & 94.1 \\
Medio alto & 62.0 & 77.8 & 97.0 & 55.4 & 97.7 \\
Alto & 79.7 & 89.7 & 96.9 & 61.3 & 99.6 \\
Nacional & 44.3 & 56.4 & 92.5 & 45.9 & 92.5 \\
\hline
\end{tabular}

Fuente: INEGI. Encuesta Nacional sobre Disponibilidad y Movilidad de la Población.

Esta es la realidad que la información sociodemográfica describe y no creemos que se haya tomado en cuenta al implementar las medidas no farmacológicas para enfrentar la pandemia.

\section{Movilidad cotidiana de la población}

Para enfrentar una pandemia, el mundo contemporáneo que ha incorporado en su vida cotidiana de las décadas recientes los avances científicos más significativos de la historia de la humanidad, paradójicamente, tiene que enfrentar las consecuencias de la globalización que fomenta la movilidad de la población y las mercancías, con tal intensidad y cobertura espacial, que facilita la expansión de las enfermedades transmisibles.

En México, como en la mayoría de las naciones en que la pandemia ha sido especialmente devastadora en términos de la pérdida de vidas humanas, los vectores iniciales de transmisión del virus SARS-CoV-2 fueron personas que regresaban a México después de su estancia en otros países 
y concretamente en Estados Unidos y específicamente, en lugares de recreo en los cuales las familias de elevados ingresos acostumbran pasar sus vacaciones y por tanto, esto generó la idea de que la Covid-19 sería un "padecimiento que afectaría sólo a los ricos". ${ }^{24}$

Pero lo que podría pasar por ser sólo una anécdota, se convirtió en una serie de terror originada por la migración de personas de países en donde la elevada incidencia del SARS-CoV-2 hacía otros países, amenazaba con convertir una epidemia nacional en una pandemia global, como finalmente sucedió.

En el caso de México, los migrantes que retornaron a sus lugares de origen y las personas deportadas de Estados Unidos, se convirtieron en la fuente de contagio del exterior, antes de que los casos se produjeran en el propio lugar de residencia de las personas contagiadas y se transmitieran entre vecinos de la propia localidad.

Como sucedió con las medidas internas para evitar la propagación del virus, a partir del 21 de marzo se establecieron restricciones al tránsito terrestre no esencial entre México y Estados Unidos, pero México no adoptó restricciones para el ingreso de visitantes del extranjero y tampoco estableció controles sanitarios para el regreso al territorio nacional de mexicanos provenientes de otros países, esta situación tendría que haber sido considerada seriamente como un factor en la propagación del virus, en especial en estados de la República con un número significativo de migrantes como Michoacán, Puebla o Zacatecas, sólo para mencionar algunas entidades en las cuales se detectaban este tipo de contagios.

Es evidente que la migración internacional ha contribuido a la propagación del virus como en ninguna otra etapa de la historia documentada de la humanidad; sin embargo, este tema rebasa los objetivos de este texto, por lo que nuestro interés es hacer mención sólo a la movilidad cotidiana de la población.

Las medidas que las autoridades gubernamentales fueron promoviendo gradualmente para reducir la movilidad de las personas y hacer que "permanecieran en casa", tuvieron alcances limitados por las propias condiciones económicas de amplios sectores de la población que están obligados a desempeñar las actividades que les permiten obtener un ingreso fuera de sus hogares y a trasladarse a su lugar de trabajo a través de largas jornadas

${ }^{24}$ Un personaje conocido en los círculos empresariales y que lamentablemente falleció, fue el Presidente de la Bolsa Mexicana de Valores y otras personas que, residentes en la ciudad de Puebla, habían estado en el estado de Colorado compartiendo eventos, en los que muy probablemente se contagiaron. El Diario Cambio de Puebla reportó en nota del 19 de marzo de 2020: "Uno de los poblanos fifis que regresó de Vail con coronavirus, estuvo en diez establecimientos de Puebla, no sólo en tres". 
y en medios de transporte en los que no se puede evitar el contacto entre los usuarios. Además, los mensajes de algunas autoridades de que no era necesario usar cubreboca hicieron que la probabilidad de contagiarse entre estas personas se incrementara.

Aunque a lo largo del periodo de duración de la pandemia se fueron presentando investigaciones con resultados que podrían parecer contradictorios sobre el riesgo de contagiarse entre las personas en espacios cerrados, las evidencias cada vez son mayores sobre la probabilidad de transmisión del virus a través del aire que contiene pequeñas partículas expulsadas por personas contagiadas con el virus y su inhalación por otras personas. Anderson y coautores (Anderson et al., 2020) por ejemplo, en su investigación concluyen que: "existe amplia evidencia de que la transmisión por aerosol es una ruta importante de contagio de la enfermedad" y que: "el peso de la evidencia sugiere que suficiente protección contra la inhalación puede ser importante para detener la Covid-19". Aunque un interés mayúsculo por estudiar esta vía de contagio surgió en la actual pandemia, existían evidencias previas al respecto derivadas del estudio de enfermedades como la influenza que no se tomaron en cuenta entre las autoridades sanitarias para sugerir o incluso obligar a usar cubreboca.

Por ejemplo, un grupo de especialistas del Instituto Nacional de Salud Pública de México, a partir de una revisión de investigaciones cuyo objetivo era estimar la probabilidad de transmisión de enfermedades respiratorias agudas en el transporte público, con el interés centrado en el virus SARS-CoV-2, observaron que:

agrupando los estudios de cohorte que analizaron la incidencia de seroconversión (ésta) fue de 54 por ciento mayor (la) posibilidad de influenza A o B en personas con uso frecuente de transporte público en comparación con las personas con un uso poco frecuente del sistema de transporte público (sic)" y que: "estudios sugieren que reducir el tiempo en transporte público (no más de 30 minutos), limitar el número de pasajeros, y asegurar una adecuada ventilación de las unidades de transporte podría ayudar a reducir el contagio(López-Olmedo et al., 2020).

Es evidente que las medidas que los especialistas sugieren, son difíciles de implementar en cualquier país y más en el nuestro, por las condiciones del transporte público en general, la calidad del servicio y el tiempo de traslado, en especial en las grandes urbes. Sin embargo, creemos que desde que se identificó la circulación de virus en México, debieron promoverse medidas para reducir el contagio por medio del uso de cubreboca, lo que 
evidentemente no se hizo sino ya muy avanzada la pandemia y esto se implementó de forma tardía especialmente en la Ciudad de México.

$\mathrm{Al}$ respecto, la Encuesta Origen-Destino en Hogares de la Zona Metropolitana del Valle de México realizada por el INEGI en 2017, que es la más actual con la que contamos, ofrece información sobre el número de viajes realizados por la población en esta Zona y la duración de los mismos, lo que muestra la elevada probabilidad de contagio según las referencias mencionadas. El promedio de duración de los viajes es de 43 minutos y cualquiera que sea el propósito del viaje en ningún caso es menor a 30 minutos.

Tabla 22: Viajes realizados el día observado* entre semana por la población de seis años o más, y minutos promedio de duración del viaje por propósito del mismo. Zona Metropolitana del Valle de México, 2017

\begin{tabular}{lrrr}
\hline Propósito del viaje & Viajes & $\%$ & $\begin{array}{r}\text { Promedio } \\
\text { (minutos) }\end{array}$ \\
\hline Trabajo & $7^{\prime} 587,199$ & 22.0 & 15.0 \\
Estudio & $4^{\prime} 102,385$ & 11.9 & 51.5 \\
Regresar al hogar & $16^{\prime} 350,004$ & 47.3 & 24.0 \\
Otro propósito & $6^{\prime}, 497,480$ & 18.8 & 9.5 \\
Total & $34^{\prime} 537,068$ & 100.0 & 43.0 \\
\hline
\end{tabular}

* El día de la semana observado pudo haber sido martes, miércoles o jueves.

Fuente: INEGI. Encuesta Origen-Destino en Hogares de la Zona Metropolitana del Valle de México 2017 (EOD-17).

\section{Conclusiones}

La demografía, como una disciplina que permite explicar la evolución de cada una de las variables que constituyen su objeto de estudio, a partir de su cuantificación, la observación de sus regularidades y la identificación de sus determinantes, es una herramienta fundamental para tomar decisiones estratégicas para todas las organizaciones de la sociedad y también para responder a eventos coyunturales que afectan negativamente a la población.

La regularidad de los fenómenos demográficos ha permitido elaborar proyecciones de su evolución con gran nivel de certidumbre a través de modelos cada vez más sofisticados, alimentados con insumos cada vez más detallados y sujetos a procesos de análisis que ahora son posibles con las herramientas tecnológicas con las que actualmente cuentan los especialis- 
tas, lo que les permite procesar volúmenes de información cuyo manejo en el pasado reciente era sencillamente impensable.

El desarrollo instrumental que se ha descrito, responde a los avances teóricos que desde diversas perspectivas intentan explicar los fenómenos demográficos a partir de sus condicionantes sociales y sus determinantes directos, "a través de los cuales y sólo a través de los cuales", para usar el lenguaje clásico de especialistas como K. Davis y J. Blake (1956), la sociedad influye sobre la demografía en una sociedad concreta.

Todo esto ha permitido entender la complejidad de la sociedad moderna, a cuya complejidad contribuye la demografía por una combinación de los efectos de su crecimiento, la transformación de la estructura por edad, la mayor movilidad espacial y el incremento de la esperanza de vida.

Esta complejidad hace necesario que, en la actualidad, las decisiones de gobierno deban ser tomadas por los líderes políticos con la asesoría de especialistas en cada campo del conocimiento. Los gobernantes ejercen el poder, pero requieren del conocimiento científico para tomar decisiones de corto, mediano y largo plazo, si lo que pretenden es contribuir al desarrollo de la sociedad.

Ya los economistas clásicos advertían de los riesgos que representa el elevado crecimiento de la población si no se promovía el desarrollo tecnológico que permitiera producir los satisfactores que la gente demanda. Sus ideas fueron el origen de las políticas de población dirigidas a reducir las tasas de crecimiento demográfico a través de la anticoncepción que, como resultado, modificaron la condición de muchas mujeres al darles la posibilidad de decidir cuándo y cuántos hijos tener. La información proveniente de las encuestas especializadas realizadas en las décadas de los años 70 y 80 del siglo $\mathrm{XX}$, mostraron que las mujeres deseaban tener menos hijos que los que habían tenido las mujeres de generaciones anteriores y las agencias gubernamentales actuaron en consecuencia. Aunque las políticas controlistas en sus orígenes fueron promovidas por los centros hegemónicos, no hay duda que su efecto transformó el comportamiento reproductivo y modificó la condición social de la mujer. La información sociodemográfica sirvió para fundamentar las políticas de población.

Los demógrafos advertimos de los riesgos del proceso acelerado de envejecimiento en los países ahora denominados emergentes, en los cuales este proceso se ha producido en unas cuantas décadas, sin que las organizaciones se adapten a las necesidades que produce este cambio, pero nuestras advertencias han sido sólo parcialmente tomadas en cuenta. Aunque los intereses del mercado se han impuesto, la información sociodemográfica 
muestra, por ejemplo, el riesgo que el envejecimiento representa para la sociedad en su conjunto en caso de que no se modifiquen los arreglos institucionales y se creen las condiciones para enfrentarlo.

Los riesgos que enfrenta la sociedad moderna son una función de los peligros y las vulnerabilidades; la demografía aporta al conocimiento de estos dos componentes y este conocimiento debería ser tomado en cuenta por los líderes organizacionales en el gobierno y el sector privado.

La búsqueda y cuantificación de riesgos debería ser una constante en todas las organizaciones de la sociedad. La coyuntura actual ha hecho evidente esta necesidad y ha sido nuestra intención al elaborar este texto.

El deterioro de la salud se convierte en la principal amenaza para una sociedad que ha sido exitosa en ampliar la esperanza de vida de los individuos, pero que eventos como los que se han vivido en el año 2020, pueden reducirla. No sólo es indispensable garantizar la sobrevivencia de las personas en condiciones saludables, enfrentamos el peligro de que la propia esperanza de vida se reduzca si el conocimiento no se usa para detectar los riesgos crecientes que enfrentará la humanidad como producto de su propio desarrollo.

Las enfermedades crónico-degenerativas han sido objeto de atención de las políticas públicas en décadas recientes; sin embargo, las infecciones de origen bacterial o viral, siguen siendo una amenaza para la humanidad y el peligro que representan creemos que no ha sido suficientemente atendido.

Una llamada de atención la constituyen los brotes epidémicos relacionado con el virus del ébola que se identificó en 1976 en África y que ha reaparecido en varias ocasiones siendo el más reciente y significativo en 2014. En este caso, aunque los huéspedes naturales del virus, son los murciélagos, la transmisión más importante se produce de persona a persona. Si bien se han desarrollado vacunas, los estilos de vida y las carencias materiales de la población que reside en los países que muestran mayor incidencia del ébola, limitan el efecto de las medidas farmacológicas para enfrentarlo.

Otra llamada de atención en décadas recientes sobre el riesgo de enfrentar una enfermedad contagiosa con efectos mundiales y que, aunque con incidencia diferencial afectó a diversos sectores de la sociedad, lo constituyó el Virus de Inmunodeficiencia Humana, causante del SIDA, que ha terminado con la vida de entre 30 y 40 millones de personas desde que se inició la epidemia hasta 2019 según la agencia de la Organización de las Naciones Unidas, encargada de atenderla (ONUSIDA). Desde el descubrimiento del virus hasta el desarrollo de los antirretrovirales, la recomenda- 
ción vigente, ha sido y sigue siendo evitar los contagios porque, aunque la ciencia ha creado tratamientos efectivos, su acceso es aún limitado para millones de personas en el mundo.

La experiencia actual con la Covid-19 ha sido, lamentablemente, un ejemplo didáctico de lo que se debe y de lo que no se debe hacer, así como de lo que se puede o no se puede hacer, para enfrentar esta crisis sanitaria y el conocimiento de las condiciones sociodemográficas de cada país, debió ser un insumo importante para adelantar las consecuencias de la enfermedad y estimar el efecto que tendrían las medidas para disminuir su incidencia.

La sociedad mexicana cuenta con un sistema de información que permite el conocimiento detallado de la sociedad, por lo que no se puede decir que la carencia de datos justifica las malas decisiones de política pública o en extremo la inacción.

A pesar del surgimiento de la pandemia, México será uno de los pocos países en el contexto internacional, que contará con datos de un censo de población realizado en 2020. A reserva de evaluar este censo y reconociendo de antemano los problemas que en la actual coyuntura pudieron afectar al censo, no hay otra fuente de datos que permita conocer la situación del país con el nivel de desagregación geográfica y socioeconómica que el censo hace posible.

La evolución de la pandemia implica combinar una respuesta no farmacológica y una respuesta farmacológica para enfrentarla. En una primera fase, la inmunización a través de las vacunas disponibles ha requerido la identificación de los grupos de población vulnerables.

Además del personal médico, desde el punto de vista demográfico, aunque la población de edad avanzada constituye una prioridad por las condiciones asociadas precisamente con su edad, los datos presentados en este texto, han hecho evidente que el mayor riesgo de muerte por el coronavirus está asociado a la existencia de comorbilidades en todos los grupos de edad, lo cual no debe ignorarse.

Los datos censales muestran el crecimiento significativo en los hogares unipersonales y en una proporción importante de éstos viven personas de edad avanzada y con discapacidades, por lo que debe diseñarse una estrategia permanente para que puedan acceder a la vacunación. Esto tampoco debe ignorarse.

La respuesta farmacológica será posible implementarla a partir de los desarrollos de la química y la física aplicada, pero la demografía debe contribuir al diseño de una estrategia de atención a los problemas de salud po- 
niendo en el centro a las personas, al reconocimiento de sus características, necesidades y en especial los recursos de que disponen.

En la sociedad mexicana las soluciones a los problemas además de tener efectos limitados, carecen de oportunidad y simplemente esto último, tiene efectos desastrosos que, en el caso de la pandemia, se ven reflejados en el número de muertes. Las defunciones al terminar el año 2020, superaron los pronósticos extremos. Nuestras estimaciones permiten suponer que en el año mencionado las defunciones registradas se reflejarán en la disminución en la esperanza de vida de mexicanas y mexicanos que la demografía debe documentar puntualmente.

Para finalizar, debemos ser enfáticos en afirmar que la necesidad del conocimiento demográfico para tomar decisiones en el ámbito de la salud pública, hace indispensable el mantenimiento y ampliación de un sistema de encuestas sero-epidemiológicas, que en el pasado reciente se había puesto en marcha.

\section{REFERENCIAS BIBLIOGRÁFICAS}

Anderson, Elizabeth, Anderson, L., Turnham, Paul, Griffin, John R. and Clarke, Chester C., 2020, Consideration of the Aerosol Transmission for COVID-19 and Public Health. Risk Analysis, Vol. 40, No. 5.

Beck, Ulrich, 2006, La sociedad del riesgo: hacia una nueva modernidad. Barcelona. Paidos Ibérica.

Brienen, Nicole C.J. and Teunis, Peter F. M., 2010, The Effect of Mask Use on the Spread of Influenza During a Pandemic. Risk Analysis, Vol. 30, No.8. Pp. 12101218.

Caldwell, J. C. and Caldwell, Patt, 1988, Kinship forms, female autonomy, and fertility: what are the connections? Canberra: Australian National University, Department of Demography, paper prepared for the Rockefeller Foundation Workshop on the Status of Women in Relation to Fertility and Mortality, Bellagio, Italy.

Cain, Mead, 1989, Family structure, Women Status and Fertility change. In: International Population Conference/Congress International de la Population, New Delhi. International Union for the Scientific Study of Population [IUSSP]. Vol.1, Pp. $181-188$

CDC, 2020, The Epidemiological Characteristics of an Outbreak of 2019 Novel Coronavirus Diseases (COVID-19) - China, 2020[J]. China CDC Weekly, 2020, 2(8): 113-122. doi: 10.46234/ccdcw2020.032. The Novel Coronavirus Pneumonia Emergency Response. Epidemiology Team. Chinese Center for Disease Control and Prevention.

Consejo de Salubridad General, 2020, Guía de Bioética de Asignación de Recursos de Medicina Crítica. México. 
Davis, Kingsley and Blake, Judith, 1956, Social Structure and Fertility: An Analytic Framework. Economic Development and Cultural Change 4(3):211-235. April 1956

González, Gabriela del Carmen; Caballero Hoyos, José Ramiro y Chávez Méndez, Ma. Guadalupe, 2011, Las metáforas de la influenza humana A (H1N1) en México: el escenario nacional al descubierto. Una aproximación a través de la prensa mexicana. Comunicación y Sociedad. Nueva época, núm. 16, julio-diciembre, pp. 105-132.

González-González, Palloni, C.A. y Wong R., 2015, Mortalidad y su asociación con enfermedades crónicas e infecciosas en México. Análisis sobre adultos mayores con datos de panel. Salud Pública México 2015; 57 supl 1:S39-S45.

Gutiérrez-Gómez, Víctor Manuel; Orenday Aréchiga, María Elena y Gutiérrez-Gómez, Adriana A., 2009, Influenza A (H1N1) 2009, epidemiología de la pandemia, valoración clínica y diagnóstico. Archivos de Investigación Materno Infantil, vol. I, núm. 2 mayo-agosto, pp. 64-74.

Hernández-Ávila, Mauricio; Gutiérrez, Juan Pablo y Reynoso-Noverón, Nancy, 2013, Diabetes mellitus en México. El estado de la epidemia. Salud Pública México, 55 supl 2:S129-S136.

Hernández Bringas, Héctor, 2020, Mortalidad por COVID-19 en México. Notas Preliminares para un Análisis Sociodemográfico. Notas de Coyuntura del CRIM. No. 36. Junio.

Horton, Richard, 2020, Comment. Offline: COVID-19 is not a pandemic. The Lancet. Vol 396 September 26, 2020

INEGI, 2019, Encuesta Nacional de la Dinámica Demográfica 2019, ENADID. Diseño muestral. Instituto Nacional de Estadística y Geografía. México.

Kritz, Mary y Gurak, Douglas, T., 1989, Women's Status, Education and Family formation in Sub-Saharan Africa. International Family Planning Perspectives, vol. 15, núm. 3, pp. 100-105.

Lima-Costa, María Fernanda, 2020, Envejecimiento en Brasil y coronavirus: iniciativa ELSI-Covid-19. Cadernos de Saúde Pública, 36 Sup 3.

Lozano, Rafael, Franco, Marina F. y Solís P., 2007, El peso de la enfermedad crónica en México: retos y desafios ante la creciente epidemia. Salud Pública de México, vol. 49 (supl1) pp.283-287.

Lozano, Rafael, Gómez-Dantés, Héctor, Garrido-Latorre, F.; Jiménez-Corona, A., Campuzano-Rincón, JC, Franco-Marina, F., Medina-Mora, Me, Borges, G., Nagavi, M., Wang, H., Vos, T., López, Ad y Murray, CJL, 2013, La carga de enfermedad, lesiones, factores de riesgo y los desafios para el sistema de salud en México. Salud Pública México, Vol.55:580-594.

López-Olmedo, Nancy; Stern, Dalia, Pérez-Ferrer, Carolina, González-Morales, Romina, Canto-Osorio, Francisco y Barrientos-Gutiérrez, Tonatiuh, 2020, Revisión rápida: probabilidad de contagio por infecciones respiratorias agudas en el 
transporte público y medidas para mitigarlo. Diseminación rápida SPM | Fecha: 19 de mayo de 2020 .

Mason, Karen, 1984, The status of Women: A Review of its relationships to Fertility and Mortality. The Rockefeller Foundation. New York.

Murray, CJL y Lopez, AD, (eds.), 1996, The global burden of disease: a comprehensive assessment of mortality and disability from diseases, injuries and risk factors in 1990 and projected to 2020. Cambridge, Harvard University Press (Global Burden of disease and Injury Series, vol. 1).

OIM, 2020, Efectos de la Covid-19 en la población migrante. Principales Hallazgos. Sondeo en América Central y México. Junio 2020. Organización Internacional para las Migraciones. Oficina Regional para Centroamérica, Norteamérica y el Caribe.

OPS, OMS, 2020, Orientación internacional para la certificación y clasificación (codificación) del Covid-19 como causa de muerte. Organización Panamericana de la Salud. Organización Mundial de la Salud.

Pérez-Rico, Raimundo, Sesma, Sergio y Puentes, Esteban, 2005, Gastos catastróficos por motivos de salud en México: estudio comparativo por grado de marginación. Salud Pública México. Vol. 47, Suplemento No. 1, pp. 47-53.

Rojas-Martínez, R; Basto-Abreu, A; Aguilar-Salinas Ca; Zárate-Rojas E Y Villalpando S, Barrientos-Gutiérrez T., 2018, Prevalencia de diabetes por diagnóstico médico previo en México. Salud Pública México; 60:224-232.

Safilios-Rothschild, Constantina, 1985, The status of women and fertility in the Third World in the 1970-1980 decade. Working Papers, No. 118. Population Council, Center for Policy Study. New York.

Singer Merrill, Bulled, Nicola, Ostrach, Bayla, and Emily Mendenhall, 2017, Syndemics and the biosocial conception of health. The Lancet. Volume 389, ISSUE 10072, pp. 941-950.

Sojo, Ana, 2003, "Vulnerabilidad social, aseguramiento y diversificación de riesgos en América", en Revista de la CEPAL. 80, pp. 121-140.

Ware Helen, 1981, Women, Demography and Development. Canberra. Australian National University Press.

\section{RESUMEN CURRICULAR DE LOS AUTORES}

\section{Carlos Welti Chanes}

Es economista, sociólogo y demógrafo por la Universidad de Chicago. Es investigador titular del Instituto de Investigaciones Sociales de la Universidad Nacional Autónoma de México (UNAM). Es miembro del Sistema Nacional de Investigadores desde su fundación. Ha sido presidente de la Sociedad Mexicana de Demografía, coordinador general del Programa Latinoamericano de Actividades en Población y vicerrector de Investiga- 
ción y Estudios de Posgrado de la Universidad Autónoma de Puebla. Es profesor de Análisis Cuantitativo del posgrado en la Facultad de Ciencias Políticas y Sociales de la UNAM. Es miembro del Consejo de Administración de la Asociación Mexicana de Planificación Familiar (MEXFAM) y preside su comité técnico. Ha publicado un gran número de trabajos sobre la fecundidad.

Dirección electrónica: welti@servidor.unam.mx

\section{Alfonso Carlos Ramírez Penagos}

Es Licenciado en Economía por la Facultad de Economía de la Universidad Nacional Autónoma de México (UNAM), donde obtuvo también el título de Especialidad en Desarrollo Social, además de contar con estudios de Maestría en Demografía Social en el Programa de Posgrado de Ciencias Políticas y Sociales (PPCPyS) de la UNAM. Ha sido asesor durante la LIX Legislatura de la Cámara de Diputados, así como de la Comisión de Fortalecimiento al Federalismo de ésta y asesor del Subsecretario de Educación Básica. Con trayectoria en el sector privado, también se ha desempeñado como consultor en proyectos de inversión rural y ha participado como integrante colaborador del Comité Técnico de Evaluación del Padrón Electoral 2017-2018 y 2020-2021 del Instituto Nacional Electoral (INE). También ha colaborado como investigador del Grupo Técnico Especializado en la Medición del Ingreso y el Bienestar (GTMIB) del INEGI- EQUIDE IBERO de 2019 a 2020.

Dirección electrónica: acrpenagos@gmail.com

Registro ORCID: https://orcid.org/0000-0003-0552-4762 